\title{
The Fragmentation of Melamine: A Study via Electron-Impact Ionization, Laser-Desorption Ionization, Collision-Induced Dissociation, and Density Functional Calculations of Potential Energy Surface
}

\author{
Shan-Shan Ju, ${ }^{\dagger}$ Chau-Chung Han, ${ }^{*, \dagger}$ Chung-Jen Wu, Alexander M. Mebel, ${ }^{\dagger}$, and \\ Yit-Tsong Chen*, \\ Institute of Atomic and Molecular Sciences, Academia Sinica, P.O. Box 23-166, Taipei 106, \\ Taiwan, Republic of China, Department of Chemistry, National Taiwan University, Taipei 106, \\ Taiwan, Republic of China, and Department of Chemistry, Tamkang University, Tamsui 25137, \\ Taiwan, Republic of China
}

Received: August 11, 1998; In Final Form: October 14, 1998

\begin{abstract}
We have studied the fragmentation of the melamine (2,4,6-triamino-s-triazine) molecule and its deuterated counterparts via electron impact ionization (EI), laser desorption ionization (LDI), and collision-induced dissociation (CID). Our EI and LDI measurements show that the dissociation of melamine is different from the concerted triple dissociation pathway of s-triazine. In EI experiments, the protonated and parent melamine ion $\left(m / z=127\left(\mathrm{C}_{3} \mathrm{~N}_{6} \mathrm{H}_{7}{ }^{+}\right)\right.$and $\left.126\left(\mathrm{C}_{3} \mathrm{~N}_{6} \mathrm{H}_{6}{ }^{+}\right)\right)$were formed initially with 20 and $70 \mathrm{eV}$ electron bombardment. Other fragment ions, such as $m / z=43\left(\mathrm{CN}_{2} \mathrm{H}_{3}{ }^{+}\right), 53\left(\mathrm{C}_{2} \mathrm{~N}_{2} \mathrm{H}^{+}\right), 56\left(\mathrm{CN}_{3} \mathrm{H}_{2}^{+}\right), 68\left(\mathrm{C}_{2} \mathrm{~N}_{3} \mathrm{H}_{2}^{+}\right), 83\left(\mathrm{C}_{2} \mathrm{~N}_{4} \mathrm{H}_{3}{ }^{+}\right)$, $85\left(\mathrm{C}_{2} \mathrm{~N}_{4} \mathrm{H}_{5}{ }^{+}\right), 99\left(\mathrm{C}_{2} \mathrm{~N}_{5} \mathrm{H}_{5}^{+}\right), 110\left(\mathrm{C}_{3} \mathrm{~N}_{5} \mathrm{H}_{4}{ }^{+}\right)$, etc., were subsequently formed from the decomposition of metastable melamine ions. This speculation was supported by our additional CID measurements. On the other hand, in the LDI experiments the melamine molecule was pumped to $1^{1} \mathrm{~A}^{\prime \prime}$ and $2^{1} \mathrm{~A}^{\prime}$ excited electronic states, respectively, with 266 and $193 \mathrm{~nm}$ lasers. In view of the same fragment ions $\left(\mathrm{m} / z=43,45\left(\mathrm{CN}_{2} \mathrm{H}_{5}{ }^{+}\right)\right.$, $60\left(\mathrm{CN}_{3} \mathrm{H}_{6}{ }^{+}\right), 85$, and 127) resulting from the different excited $1^{1} \mathrm{~A}^{\prime \prime}$ and $2^{1} \mathrm{~A}^{\prime}$ states, we conclude that the fragmentation of melamine in LDI proceeds via internal conversion to its ground potential energy surface $\left(1^{1} \mathrm{~A}^{\prime}\right)$ prior to dissociation. The decomposition mechanism in the ground electronic state has been investigated using the density functional B3LYP/6-31G* and B3LYP/cc-pVTZ methods. All the molecular ions observed in EI experiments can be produced from major and minor neutral fragments of melamine dissociation. The calculations demonstrate the reaction pathways leading to these fragments and predict the corresponding activation energies. The dissociation mechanism of melamine is shown to be distinct from that of s-triazine, because of the presence of mobile hydrogen atoms in the amino groups.
\end{abstract}

\section{Introduction}

The decomposition of melamine (2,4,6-triamino-s-triazine, Figure 1, the geometry and vibrational frequencies of which had been reported in ref 1) and its derivatives has been a subject of studies in clinical, ${ }^{2}$ agricultural, ${ }^{3}$ environmental, ${ }^{4}$ and energetic $^{5}$ applications. Melamine, serving as a spumific compound, has ever-increasing importance in plastics industry as flame and heat retardant. ${ }^{6}$ Upon the decomposition of the spumific compounds, large quantities of nonflammable gases (e.g., $\mathrm{N}_{2}$ ) are produced causing the char to bubble and a thick insulating coating is thus produced. ${ }^{7}$

In contrast to the well-studied photodissociation of 1,3,5triazine, yielding three symmetric three-body fragmentary $\mathrm{HCN}$ molecules, ${ }^{8-11}$ the decomposition of melamine with detailed quantum-state analysis has not yet been reported. In a recent research project, we have attempted to study the isomerization dynamics of some floppy molecules, such as isocyanogen $(\mathrm{CNCN}) \leftrightarrow$ cyanogen $(\mathrm{NCCN})$, protonated carbodiimide $\left(\mathrm{H}_{2}-\right.$

* To whom all correspondence should be addressed. Institute of Atomic and Molecular Sciences, Academia Sinica, P.O. Box 23-166, Taipei, Taiwan. Internet:ytchen@pub.iams.sinica.edu.tw. Fax:+886 2-2362-0200.

$\dagger$ Institute of Atomic and Molecular Sciences.

$\doteqdot$ Department of Chemistry, National Taiwan University.

$\S$ Department of Chemistry, Tamkang University.
$\left.\mathrm{NCNH}^{+}\right) \leftrightarrow$ protonated cyanamide $\left(\mathrm{NCNH}_{3}{ }^{+}\right)$, protonated isocyanogen $\left(\mathrm{HCNCN}^{+} \leftrightarrow \mathrm{CNCNH}^{+}\right)$, etc., by high-resolution laser spectroscopy. We tried to generate these species from the decomposition of melamine. We have carried out this decomposition experiment via electron-impact ionization (EI), laserdesorption ionization (LDI), and collision-induced dissociation (CID), in which the fragments from melamine were detected by time-of-flight (TOF) mass spectrometry. In this experiment, we observed a variety of interesting protonated molecular ions, which provide us with not only information about the fragmentation of melamine via different dissociation channels but also intriguing candidates for future study of isomerization in floppy molecular ions.

In this work, we studied the dissociation of melamine, and compared its much more complicated decomposition mechanism with the simple concerted triple photodissociation of 1,3,5triazine. We experimentally examined the fragmentation of melamine via EI and LDI methods. With EI, we have investigated the fragmentation channels at different electron energies. With LDI, the dissociation channels via different excited electronic states of melamine, pumped with different laser wavelength, have also been examined. Ab initio calculations have assisted in identifying the electronic states of melamine used in LDI. Experimentally, we applied CID of melamine with 


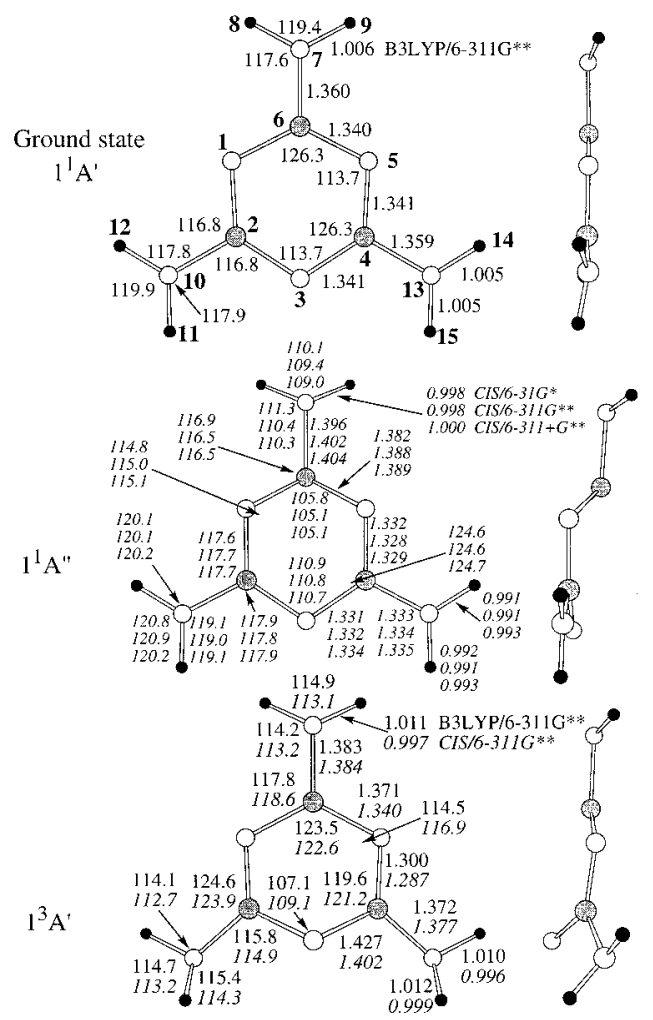

Figure 1. The calculated geometries of melamine (bond lengths in angstroms, bond angles in degrees) in the ground state (at the B3LYP/ 6-311G** level), the first singlet excited $1^{1} \mathrm{~A}^{\prime \prime}$ state (at CIS/6-31G*, CIS/6-311G** and CIS/6-311+G**), and the lowest triplet $1^{3} \mathrm{~A}^{\prime}$ state (at B3LYP/6-311G** and CIS/6-311G**).

Ar atoms to facilitate understanding the decomposition mechanism of melamine.

To understand the detailed decomposition mechanism of melamine in EI and LDI, a careful study of potential energy surface (PES) for both ionized and neutral ground and excited states from melamine to its dissociation fragments is required. In this paper, we investigate the neutral ground-state surface leading to various major and minor decomposition products. The best experimental test for this PES would be a gas-phase experiment on dissociation of melamine. Meanwhile, our study is relevant to the LDI measurements assuming that the internal conversion precedes the dissociation. It should be noted though that only a fraction of dissociation products is ionized and can be seen in the LDI mass spectra, while the neutral products could not be detected by this technique. Some molecular ions observed in EI can be formed from the neutral dissociation products by protonation.

This paper is organized as follows. In section 2, experimental details of EI, LDI, CID, and TOF mass spectrometry are described. We have also observed the absorption spectra of melamine in water/methanol mixture $(200-500 \mathrm{~nm})$ to compare with the calculated low-lying electronic states of melamine. The calculation is described in section 3. Experimental and theoretical results are presented in section 4 . The analysis of experimental data is given in section 5. The calculated PES for fragmentation of melamine is described in section 6. Concluding remarks are addressed in section 7.

\section{Experimental Details}

2.1. Sample Handling. The melamine sample purchased from Janssen Chimica was used without further purification. The deuterated melamine was prepared by heating melamine in
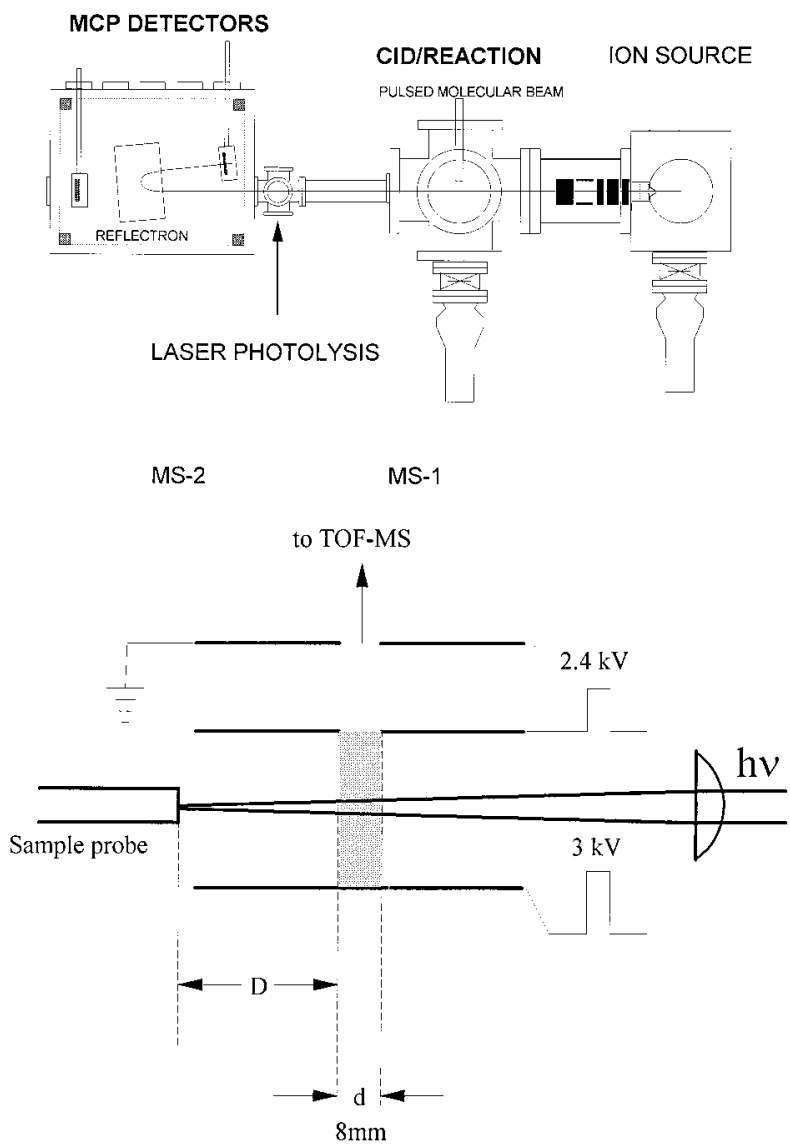

Figure 2. (a) The RTOF-CID-MS system. The parent ions are generated inside the ion source chamber. The collision gas, Ar, is injected into the CID/REACTION chamber via a pulsed molecular beam nozzle. (b) Laser desorption/photolysis region of the ion source.

excess $\mathrm{D}_{2} \mathrm{O}$. Partially deuterated melamine, abbreviated as melamine- $d_{x} h_{6-x}$, was obtained by heating the melamine- $\mathrm{D}_{2} \mathrm{O}$ mixture at about $60{ }^{\circ} \mathrm{C}$ for several hours. Fully deuterated melamine, melamine- $d_{6}$, was obtained by boiling melamine$d_{x} h_{6-x}$ in $\mathrm{D}_{2} \mathrm{O}$ until the solvent was completely driven away.

2.2. Ultraviolet/Visible Absorption Spectra. The ultraviolet/ visible (UV/vis) absorption spectra of melamine dissolved in water and water/methanol mixture have been recorded with a commercial UV/vis spectrometer in the range of 200-500 nm. These spectra are compared with the theoretically calculated excited electronic states of melamine. The identification of the electronic states helps to interpret which excited electronic state is involved in the LDI experiments, where different intermediate states may be responsible for different dissociation channels in photodissociation.

2.3. Electron-Impact Ionization. Melamine and melamine$d_{6}$ mounted on a direct insertion probe were ionized with 20 and $70 \mathrm{eV}$ electron beams, and the products were detected by a Finnigan mass spectrometer (Model TSQ-46C). The resultant EI mass spectra in the mass range of 40-140 amu were recorded.

2.4. Laser-Desorption Ionization. Saturated melamine/ $\mathrm{H}_{2} \mathrm{O}$ (or melamine- $d_{x} h_{6-x} / \mathrm{D}_{2} \mathrm{O}$, or melamine- $d_{6} / \mathrm{D}_{2} \mathrm{O}$ ) solution was applied over the tip of a stainless steel probe, and the solvent was allowed to dry out in ambient air leaving behind a loose layer of melamine deposit. The sample probe was then sent into the ion source chamber maintained at $10^{-7}-10^{-8}$ Torr range (Figure 2a). A detailed description of the LDI procedure and mass spectra acquisition can be found in the previous work. ${ }^{12,13}$ The ablation laser is either a $266 \mathrm{~nm}$ laser with $8 \mathrm{~ns}$ pulse width 
(Lumonics HY750 Nd:YAG laser), or a $193 \mathrm{~nm}$ laser with 15 ns pulse width (Lumonics EX742 excimer laser). A $25 \mathrm{~cm}$ focusing lens was used as the entrance window to the ion source chamber. The $266 \mathrm{~nm}$ beam was reduced to a spot of $1 \mathrm{~mm}$ in diameter at the sample surface. The $193 \mathrm{~nm}$ beam passed through a telescope consisted of two focusing lenses $(f=15$ $\mathrm{cm}$ ) and was reduced into a $23 \mathrm{~mm}^{2}$ rectangular spot in front of the entrance window.

As shown in Figures $2 \mathrm{a}$ and $\mathrm{b}$, the desorbed species are allowed to drift $33 \mathrm{~mm}$ parallel to the plates comprising the first acceleration region of a Wiley-McLaren ion source before they are extracted perpendicularly into a reflection TOF mass spectrometer (RTOF-MS). The ion extraction apertures are 8 $\mathrm{mm}$ in diameter, and the ion extraction is accomplished by applying two synchronous high voltage pulses (one fixed at 3000 $\mathrm{V}$ and the other adjusted about $2400 \mathrm{~V}$ for optimizing mass resolution, rise time $\sim 70 \mathrm{~ns}$ ) to the two ion acceleration electrodes flanking the sample probe. The kinetic energy of the free-flying ions is approximately $2700 \mathrm{eV}$ and postaccelerated to $5000 \mathrm{eV}$ just prior to their detection by a microchannel plate (MCP) detector assembly. Mass spectra can be recorded at ion extraction delay times (with respect to desorption laser pulse) of $8-35 \mu \mathrm{s}$.

The relative intensities of the observed ionic species vary with the delay time as well as laser conditions under which the mass spectrum is taken. The LDI mass spectra in our experiments were collected at different delay times and laser conditions that gave the best overall qualitative appearance. Generally speaking, the heavier the ion is the slower it drifts toward the ion sampling region and it is preferentially detected at longer delay times. As a result, no quantitative interpretation of the relative ion abundance is attempted throughout this work.

2.5. Collision-Induced Dissociation/Tandem Mass Spectrometry. The sample coating technique described in section 2.4 is not ideal, since the loose layer of melamine deposit is vulnerable to mechanical vibration. In CID experiments, melamine films were coated onto the stainless steel probe via vapor deposition under $10^{-2}$ Torr vacuum. The two sample preparation techniques yielded qualitatively identical mass spectra. A 266 $\mathrm{nm}$ laser beam was used for desorption. The parent ions extracted from the ion source were intersected by a pulsed Ar atomic beam delivered from a pulsed valve (General Valve Series-9) at backing pressure of 40 psig in the CID/REACTION chamber located in the field-free region between the ion source and the reflectron (Figure 2a). As a result of ion-neutral collisions, daughter ions were generated. These daughter ions were energy analyzed and refocused by a reflectron at the MCP detector.

The reflecting voltage applied to the reflectron was reduced to $V_{\mathrm{d}}$ to temporally focus daughter ions to the same TOF as their parent ions under the full reflecting potential $\left(V_{\mathrm{p}}\right)$. The daughter-ion spectrum was collected by recording each $V_{\mathrm{d}}$. The mass of the daughter ion $\left(M_{\mathrm{d}}\right)$ is then determined from $M_{\mathrm{d}}=$ $M_{\mathrm{p}} V_{\mathrm{d}} / V_{\mathrm{p}}$, where $M_{\mathrm{p}}$ is the mass of parent ion. Daughter-ion scans were performed for the chosen parent ions of $\mathrm{m} / \mathrm{z}=127$ and of $m / z=60$ to diagnose their structures. Two delay generators (Stanford Research System DG535) were used to control the sequence timings of the pulsed laser, pulsed molecular beam valve, and data acquisition.

\section{Computation}

Theoretical calculations of the vertical and adiabatic excitation energies for several electronically excited states of melamine have been performed using various ab initio molecular-orbital methods. These include (1) the configuration interaction method with single excitations (CIS) ${ }^{14}$ and the $6-31 G^{*}, 6-311 G^{* *}$, and $6-311+\mathrm{G}^{* *}$ basis sets ${ }^{15,16}$ and (2) multireference CASSCF and CASPT2 methods ${ }^{17}$ with the ANO basis set ([10s6p3d]/(3s $\left.2 \mathrm{p} 1 \mathrm{~d}\right)$ for $\mathrm{C}$ and $\mathrm{N},[7 \mathrm{~s}] /(2 \mathrm{~s})$ for $\mathrm{H}$ atoms $).{ }^{18}$ For the lowest triplet state, we additionally performed the calculations using the hybrid density functional B3LYP method. ${ }^{19}$ Geometry of the lowest singlet excited state has been optimized at the CIS level with various basis sets and geometry of the lowest triplet state has been calculated employing CIS/6-311G** and B3LYP/6$311 \mathrm{G}^{* *}$. Vibrational frequencies for the lowest excited singlet and triplet states have been computed using CIS/6-31G* and B3LYP/6-311G**, respectively, to characterize the nature of the stationary points on the electronically excited PESs. Earlier, ${ }^{1}$ we have shown that for the ground state of melamine, the HF method corresponding to CIS for excited states and B3LYP give very similar geometries. As will be shown below, the CIS and B3LYP optimized structures for the $1^{3} \mathrm{~A}^{\prime}$ are also close. Therefore, the comparison between the geometries obtained by these two methods is warranted.

In the ground electronic state, the geometries of various isomers of melamine, its dissociation fragments, and transition states along the dissociation pathways have been optimized at the B3LYP/6-31G* level. Vibrational frequencies have been calculated at the same level for characterization of the nature of stationary points and zero-point energy corrections (ZPE). All local minima have been confirmed to have zero imaginary frequencies and transition states to have one imaginary frequency. Unless otherwise mentioned, all energies quoted in the paper include ZPE. To confirm the connections between local minima and transition states, we carried out intrinsic reaction coordinate (IRC) calculations. ${ }^{20}$ The relative energies for the most important isomers, dissociation products, and transition states have been refined at the B3LYP level with Dunning's cc-pVTZ basis set. ${ }^{21}$ The GAUSSIAN $94^{22}$ and MOLCAS-323 programs were used for the calculations.

A recent study of Rice and co-workers ${ }^{24}$ on the PES of S-triazine reactions demonstrated that the performance of the B3LYP method both for geometries and energies is very good and comparable with that of ab initio QCISD(T). The most accurate results for the heat of the $\mathrm{C}_{3} \mathrm{~N}_{3} \mathrm{H}_{3} \rightarrow 3 \mathrm{HCN}$ reaction were obtained at the B3LYP/cc-pVTZ level. Therefore, for the larger system such as melamine, B3LYP is the best choice for a detailed study of PES, the expected results of which are accurate at least semiquantitatively.

\section{Experimental and Computational Results}

4.1. Absorption Spectra and Calculated Electronic States. The observed UV/vis absorption spectrum of melamine shows a peak at $\sim 275 \mathrm{~nm}$ with HWHM of $\sim 25 \mathrm{~nm}$, where melamine was dissolved in the water/methanol mixture $(\mathrm{v} / \mathrm{v})$ of $3 / 7$. The peak shifts to $\sim 260 \mathrm{~nm}$ when melamine is dissolved in a mixture of 5:5 and merges into a very strong band of 200-240 nm when melamine is dissolved in pure water. The distinct blue shift due to solvent polarity has indicated that the peak at $\sim 275 \mathrm{~nm}$ is responsible for the $n-\pi^{*}$ transition. The very strong band at $\sim 200-240 \mathrm{~nm}$ is characterized by the $\pi-\pi^{*}$ transition.

Calculated excitation energies for the lowest lying four excited singlets and three triplets of melamine are shown in Table 1. The lowest excited singlet is $1^{1} \mathrm{~A}^{\prime \prime}$ and its energy at the CIS/ $6-31 \mathrm{G}^{*}$ level is calculated to be $7.49 \mathrm{eV}$. The use of the larger basis sets, $6-311 \mathrm{G}^{* *}$ and $6-311+\mathrm{G}^{* *}$ does not significantly change the excitation energy; the value obtained with CIS/6$311+\mathrm{G}^{* *}$ is $7.32 \mathrm{eV}$. On the other hand, the use of more 
TABLE 1: Electronic Excitation Energies (eV) of Melamine Calculated at Various Theory Levels

\begin{tabular}{|c|c|c|c|c|c|c|c|c|c|}
\hline \multirow[b]{2}{*}{ method } & \multicolumn{2}{|c|}{$1^{1} \mathrm{~A}^{\prime \prime}$} & \multirow{2}{*}{$\begin{array}{c}2^{1} \mathrm{~A}^{\prime} \\
\text { (vert.) }\end{array}$} & \multirow{2}{*}{$\begin{array}{l}2^{1} \mathrm{~A}^{\prime \prime} \\
\text { (vert.) }\end{array}$} & \multirow{2}{*}{$\begin{array}{c}3^{1} \mathrm{~A}^{\prime} \\
\text { (vert.) }\end{array}$} & \multicolumn{2}{|c|}{$1^{3} \mathrm{~A}^{\prime}$} & \multirow{2}{*}{$\begin{array}{l}1^{3} \mathrm{~A}^{\prime \prime} \\
\text { (vert.) }\end{array}$} & \multirow{2}{*}{$\begin{array}{c}2^{3} \mathrm{~A}^{\prime} \\
\text { (vert.) }\end{array}$} \\
\hline & vert. & adiab. & & & & vert. & adiab. & & \\
\hline CIS/6-31G* & 7.49 & 6.58 & 8.52 & 8.09 & 8.23 & 5.86 & 5.69 & 6.53 & 6.54 \\
\hline CIS/6-311G** & 7.49 & 6.54 & 8.31 & 8.10 & 8.16 & 5.88 & 5.74 & 6.54 & 6.54 \\
\hline CIS/6-311+G** & 7.32 & 6.39 & 7.42 & 7.34 & 7.34 & 5.84 & 5.71 & 6.44 & 6.45 \\
\hline B3LYP/6-31G* & & & & & & 5.04 & 4.25 & & \\
\hline B3LYP/6-311G** & & & & & & 5.37 & 4.27 & & \\
\hline B3LYP/6-311+G** & & & & & & 5.25 & 4.21 & & \\
\hline CASSCF $(4,4) / \mathrm{ANO}$ & 7.49 & & & & 8.41 & 6.04 & & 6.76 & \\
\hline CASPT2 $(4,4) / A N O$ & 4.83 & & & & 6.89 & 4.17 & & 4.98 & \\
\hline $\operatorname{CASSCF}(14,12) / \mathrm{ANO}$ & 6.07 & 5.30 & 6.57 & 7.70 & 7.65 & 4.84 & 4.05 & 6.22 & 6.34 \\
\hline CASPT2 $(14,12) / \mathrm{ANO}$ & 4.72 & 4.28 & 6.43 & 6.94 & 6.87 & 4.38 & 3.61 & 4.89 & 4.81 \\
\hline oscillator strength $^{a}$ & $2.5 \times 10^{-5}$ & & 0.0256 & $7 \times 10^{-4}$ & $3 \times 10^{-4}$ & 0.0 & & 0.0 & 0.0 \\
\hline
\end{tabular}

${ }^{a}$ Calculated at the CIS/6-311+G** level.

sophisticated theoretical methods decreases the calculated excitation energy dramatically. While $\operatorname{CASSCF}(4,4)$ with the active space containing four electrons distributed at four orbitals gives the same result as that of CIS, $\operatorname{CASSCF}(14,12)$ lowers the excitation energy to $6.07 \mathrm{eV}$. Upon taking into account the dynamic correlation using the CASPT2 approach, the energy of $1^{1} \mathrm{~A}^{\prime \prime}$ further decreases to 4.83 and $4.72 \mathrm{eV}$, respectively, with the $(4,4)$ and $(14,12)$ active spaces. The CASPT2 method is expected to provide the excitation energies with an accuracy of better than $0.25 \mathrm{eV} .{ }^{25}$ Therefore, we conclude that the $1^{1} \mathrm{~A}^{\prime \prime}$ $\leftarrow 1^{1} \mathrm{~A}^{\prime}$ excitation energy for melamine lies in the interval of $4.6-4.9 \mathrm{eV}$ or $269-253 \mathrm{~nm}$ with an oscillator strength of 2.5 $\times 10^{-5}$. The analysis of the wave function shows that the $1^{1} \mathrm{~A}^{\prime \prime}$ $\leftarrow 1^{1} \mathrm{~A}^{\prime}$ transition can be described as a mixture of $n-\pi^{*}$ and $\pi-\pi^{*}$, with contribution from $n-\pi^{*}$ being dominant. The mixing is due to the interaction of the $n$ orbitals of aminonitrogens with the aromatic $\pi$ system.

The next singlet state, $2^{1} \mathrm{~A}^{\prime}$, also has a mixed $\pi / n-\pi^{*}$ character, but the dominant configuration is $\pi-\pi^{*}$. At our best CASPT2 $(14,12)$ level, the vertical excitation energy is $6.43 \mathrm{eV}$. The $2^{1} \mathrm{~A}^{\prime} \leftarrow 1^{1} \mathrm{~A}^{\prime}$ transition has a large oscillator strength of 0.026 . The next two singlet excited states, $2^{1} \mathrm{~A}^{\prime \prime}$ and $3^{1} \mathrm{~A}^{\prime}$, have similar energies, 6.94 and $6.87 \mathrm{eV}$ at the CASPT2(14,12)/ANO level. The main contributions to the CASSCF wave functions of these states come from $n-3 \mathrm{~s}$ transitions. The calculated oscillator strengths for both states are low, $3 \times 10^{-4}$ for the former and $7 \times 10^{-4}$ for the latter.

The lowest $1^{3} \mathrm{~A}^{\prime}$ triplet state of melamine has $n / \pi-\pi^{*}$ character. Our best estimate for the $1^{3} \mathrm{~A}^{\prime} \leftarrow 1^{1} \mathrm{~A}^{\prime}$ excitation energy is $4.38 \pm 0.2 \mathrm{eV}$. The energy of the first triplet state of melamine is similar to that of s-triazine; ${ }^{10}$ comparable CASSCF$(14,12)$ and $\operatorname{CASSCF}(12,9)$ approximations give the values of 4.84 and $4.59 \mathrm{eV}$, respectively, for melamine and s-triazine. The next $1^{3} \mathrm{~A}^{\prime \prime}$ state is also of the $n / \pi-\pi^{*}$ character. The best CASPT2 $(14,12)$ calculated energy for this state is $4.89 \mathrm{eV}$. The $1^{3} \mathrm{~A}^{\prime \prime}$ state is virtually degenerated with $2^{3} \mathrm{~A}^{\prime}$.

Optimized geometries of the $1^{1} \mathrm{~A}^{\prime \prime}$ and $1^{3} \mathrm{~A}^{\prime}$ electronic states are presented in Figure 1 in comparison with the ground-state geometry. Both excited states keep the $C_{\mathrm{s}}$ symmetry of the ground state with the symmetry plane perpendicular to the aromatic ring. The $C_{\mathrm{s}}$ structures of the $1^{1} \mathrm{~A}^{\prime \prime}$ and the $1^{3} \mathrm{~A}^{\prime}$ states have all real frequencies indicating that these structures correspond to minima on the PESs. The aromatic system of the molecule is distorted and the ring loses its planarity. The distortions are different in the $\mathrm{A}^{\prime \prime}$ singlet and $\mathrm{A}^{\prime}$ triplet. In $1^{1} \mathrm{~A}^{\prime \prime}$, the $\mathrm{C}^{6}$ atom deviates from the $\mathrm{C}_{2} \mathrm{~N}_{3}$ plane (other five atoms of the ring) and the $\mathrm{C}^{6} \mathrm{~N}^{1}$ and $\mathrm{C}^{6} \mathrm{~N}^{7}$ bonds are elongated. Pyramidality of the $\mathrm{N}^{7}$ amino group increases, while the $\mathrm{N}^{10}$ and $\mathrm{N}^{13}$ amino groups become virtually planar. Thus, the $\pi$ system of the molecule is shifted away from $\mathrm{C}^{6}$ and $\mathrm{N}^{7}$ and accumulates on the remaining carbon and nitrogen atoms.

Relaxation of the geometry in the triplet state involves lengthening the $\mathrm{N}^{3} \mathrm{C}^{2}$ and $\mathrm{N}^{3} \mathrm{C}^{4}$ bonds from 1.34 to $1.43 \AA$ at the B3LYP/6-311G** level. The $\mathrm{N}^{3}$ atom is lifted up from the $\mathrm{N}^{1} \mathrm{C}^{2} \mathrm{~N}^{5} \mathrm{C}^{4}$ plane and pyramidality of all three amino groups significantly increases. The common $\pi$ system of the melamine molecule is destroyed and the bond alteration occurs. We expect that the $1^{3} \mathrm{~A}^{\prime}$ and open shell singlet $2^{1} \mathrm{~A}^{\prime}$ electronic states should have similar geometries. The adiabatic excitation energies, calculated at the CASPT2/ANO level, are 4.28 and $3.61 \mathrm{eV}$ for the $1^{1} \mathrm{~A}^{\prime \prime}$ and $1^{3} \mathrm{~A}^{\prime}$ electronic states, respectively.

4.2. Electron-Impact Ionization. The relative intensities of the fragmented melamine- $h_{6}$ and melamine- $d_{6}$ at 20 and $70 \mathrm{eV}$ EI mass spectra are listed in Table 2. Although the deuterated melamine in the present experiment contains various H/D substitutions, the majority of the sample is melamine- $d_{6}$ as can be seen in Table 2 . For melamine- $h_{6}$, fragment ions such as $m / z=43,53,56,68,83,85,99$ and 110 are observed. For melamine- $d_{6}$, the corresponding fragment ions are $\mathrm{m} / \mathrm{z}=46$, $54,58,70,86,90,104$ and 114. The identification of molecular formula for the fragment ions can be ascertained by the content of deuterium atoms in each fragment.

4.3. Laser-Desorption Ionization. In $266 \mathrm{~nm}$ LDI of melamine, ions with $m / z=18,23,39,43,45,60,85$, and 127 are observed as shown in Figure $3 \mathrm{a}$, where $\mathrm{m} / \mathrm{z}=127$ is the protonated melamine. The peak of $\mathrm{m} / \mathrm{z}=18 \mathrm{might}$ be ascribed to the protonated ammonia or to residual water in the chamber. Peaks at $m / z=23$ (sodium) and 39 (potassium) are frequently observed in LDI experiments from samples containing even trace amounts of these elements due to the high stability of alkali metal cations. The mass peaks at $m / z=27,52$, and 56 have their origin from background interfering species; the latter two can be ascribed to $\mathrm{Cr}^{+}$and $\mathrm{Fe}^{+}$from the stainless steel probe. The fragment ions produced in $266 \mathrm{~nm}$ LDI are listed in Table 3.

In $193 \mathrm{~nm}$ LDI of melamine, the same set of ions formed in $266 \mathrm{~nm}$ LDI are observed (Figure 3b). The products generated in the LDI of melamine- $d_{x} h_{6-x}$ and melamine- $d_{6}$ with $193 \mathrm{~nm}$ are also listed in Table 3 . The mass spectrum of melamine$d_{x} h_{6-x}$ helped us to correlate the mass spectra of melamine- $h_{6}$ and melamine- $d_{6}$. For instance, the fragment at $\mathrm{m} / z=43$ from melamine- $h_{6}$ developed into $43,44,45$, and 46 when melamine$d_{x} h_{6-x}$ was used, but only the deuterated fragment ion at $\mathrm{m} / z=$ 46 was detected for the melamine- $d_{6}$ sample. This clearly indicates the presence of three hydrogen atoms in the $\mathrm{m} / \mathrm{z}=43$ fragment.

While $\mathrm{C}_{2} \mathrm{~N}_{3} \mathrm{H}_{2}{ }^{+}(\mathrm{m} / \mathrm{z}=68)$ and $\mathrm{C}_{3} \mathrm{~N}_{5} \mathrm{H}_{4}{ }^{+}(\mathrm{m} / \mathrm{z}=110)$ are not observed in Figure 3, their deuterated counterparts clearly 
TABLE 2: Fragment Ions and Relative Intensities in the 20 and $70 \mathrm{eV}$ Electron-Impact Ionizations of Melamine

\begin{tabular}{|c|c|c|c|c|c|c|}
\hline \multirow{3}{*}{$\begin{array}{l}\text { fragment ions } \\
\left(\mathrm{m} / \mathrm{z} \text { value }^{a}\right)\end{array}$} & \multicolumn{4}{|c|}{ relative intensity ${ }^{b}$} & \multirow{3}{*}{$\begin{array}{c}\text { no. of } \\
\mathrm{H} \text { atoms }\end{array}$} & \multirow{3}{*}{$\begin{array}{l}\text { molecular } \\
\text { formula }\end{array}$} \\
\hline & \multicolumn{2}{|c|}{$20 \mathrm{eV}$} & \multicolumn{2}{|c|}{$70 \mathrm{eV}$} & & \\
\hline & $\mathrm{C}_{3} \mathrm{~N}_{6} \mathrm{H}_{6}$ & $\mathrm{C}_{3} \mathrm{~N}_{6} \mathrm{H}_{6-x} \mathrm{D}_{x}$ & $\mathrm{C}_{3} \mathrm{~N}_{6} \mathrm{H}_{6}$ & $\mathrm{C}_{3} \mathrm{~N}_{6} \mathrm{H}_{6-x} \mathrm{D}_{x}$ & & \\
\hline 41 & & & 0.278 & 0.128 & & \\
\hline 43 & 0.084 & 0.003 & 0.625 & 0.286 & 3 & $\mathrm{CN}_{2} \mathrm{H}_{3}{ }^{+}$ \\
\hline 44 & & 0.014 & 0.009 & 0.369 & & \\
\hline 45 & & 0.066 & & 0.336 & & \\
\hline 46 & & 0.167 & & 1.032 & & $\mathrm{CN}_{2} \mathrm{D}_{3}{ }^{+}$ \\
\hline$\overline{47}$ & & 0.006 & & 0.012 & & \\
\hline 53 & & & 0.028 & & 1 & $\mathrm{C}_{2} \mathrm{~N}_{2} \mathrm{H}^{+}$ \\
\hline$\underline{54}$ & & & & 0.042 & & $\mathrm{C}_{2} \mathrm{~N}_{2} \mathrm{D}^{+}$ \\
\hline$\overline{56}$ & & & 0.017 & & 2 & $\mathrm{CN}_{3} \mathrm{H}_{2}{ }^{+}$ \\
\hline 57 & & & & 0.003 & & $\sigma_{3}+\pi_{2}$ \\
\hline$\underline{58}$ & & & 0.003 & 0.029 & & $\mathrm{CN}_{3} \mathrm{D}_{2}^{+}$ \\
\hline$\overline{62}$ & & & & 0.004 & & \\
\hline 63 & & 0.003 & 0.007 & & & \\
\hline 64 & & 0.006 & & & & \\
\hline 66 & & & & 0.009 & & \\
\hline 68 & 0.017 & & 0.156 & 0.026 & 2 & $\mathrm{C}_{2} \mathrm{~N}_{3} \mathrm{H}_{2}^{+}$ \\
\hline 69 & & 0.009 & 0.006 & 0.015 & & \\
\hline 70 & & 0.025 & & 0.206 & & $\mathrm{C}_{2} \mathrm{~N}_{3} \mathrm{D}_{2}^{+}$ \\
\hline$\overline{71}$ & & & & 0.003 & & \\
\hline 83 & 0.006 & & 0.124 & & 3 & $\mathrm{C}_{2} \mathrm{~N}_{4} \mathrm{H}_{3}{ }^{+}$ \\
\hline 86 & & 0.009 & 0.006 & 0.183 & & $\mathrm{C}_{2} \mathrm{~N}_{4} \mathrm{D}_{3}^{+}$ \\
\hline$\overline{85}$ & 0.120 & 0.003 & 0.290 & 0.065 & 5 & $\mathrm{C}_{2} \mathrm{~N}_{4} \mathrm{H}_{5}^{+}$ \\
\hline 87 & & 0.012 & & 0.012 & & \\
\hline 88 & & 0.045 & & 0.021 & & \\
\hline 89 & & 0.138 & & 0.202 & & \\
\hline 90 & & 0.240 & & 0.328 & & $\mathrm{C}_{2} \mathrm{~N}_{4} \mathrm{D}_{5}^{+}$ \\
\hline$\overline{91}$ & & 0.009 & & 0.007 & & \\
\hline 99 & 0.009 & & 0.003 & & 5 & $\mathrm{C}_{2} \mathrm{~N}_{5} \mathrm{H}_{5}^{+}$ \\
\hline 102 & & 0.003 & & & & \\
\hline 103 & & 0.006 & & & & \\
\hline 104 & & 0.012 & & 0.007 & & $\mathrm{C}_{2} \mathrm{~N}_{5} \mathrm{D}_{5}{ }^{+}$ \\
\hline 110 & & & 0.003 & & 4 & $\mathrm{C}_{3} \mathrm{~N}_{5} \mathrm{H}_{4}^{+}$ \\
\hline 111 & 0.003 & & & & & \\
\hline 113 & & 0.003 & & & & \\
\hline 114 & & 0.006 & & 0.004 & & $\mathrm{C}_{3} \mathrm{~N}_{5} \mathrm{D}_{4}^{+}$ \\
\hline$\overline{126}$ & 1.000 & & 1.000 & & 6 & $\mathrm{C}_{3} \mathrm{~N}_{6} \mathrm{H}_{6}{ }^{+}$ \\
\hline 127 & 0.070 & 0.004 & 0.122 & & & $\mathrm{C}_{3} \mathrm{~N}_{6} \mathrm{H}_{7}+$ \\
\hline 128 & & 0.009 & & & & \\
\hline 129 & & 0.041 & & 0.018 & & \\
\hline 130 & & 0.208 & & 0.153 & & \\
\hline 131 & & 0.673 & & 0.707 & & \\
\hline 132 & & 1.000 & & 1.000 & & $\mathrm{C}_{3} \mathrm{~N}_{6} \mathrm{D}_{6}{ }^{+}$ \\
\hline$\overline{133}$ & & 0.074 & & 0.118 & & \\
\hline 134 & & 0.030 & & 0.087 & & \\
\hline
\end{tabular}

${ }^{a}$ The bold number represents the $m / z$ value of the fragment ion from $\mathrm{C}_{3} \mathrm{~N}_{6} \mathrm{H}_{6}$, and the underlined number indicates the fully deuterated counterpart of the fragment ion. ${ }^{b}$ Relative intensities refer to $\mathrm{C}_{3} \mathrm{~N}_{6} \mathrm{H}_{6}{ }^{+}(\mathrm{m} / \mathrm{z}=126)$ and $\mathrm{C}_{3} \mathrm{~N}_{6} \mathrm{D}_{6}{ }^{+}(\mathrm{m} / \mathrm{z}=132)$, respectively, in melamine and deuterated melamine.

exist in the corresponding LDI experiments as listed in Table 3. At earlier ion extraction delay times than that adopted for Figure $3, m / z=68$ was actually observed as a minor ionic species. The temporal profiles of the major LDI species recorded with a $266 \mathrm{~nm}$ laser have been carefully measured in a different paper and found to spread over widely different time windows. ${ }^{26}$ In that study, a detailed description of the temporal signal variation of the various ionic species generated in the LDI process has been reported. As mentioned in section 2.4, the quantitative appearance of the mass spectra can vary with many experimental variables, and this appearance may explain the minor differences present in some of the very weak ion signals in the LDI experiments.

4.4. Collision-Induced Dissociation. Daughter ions formed in the CID from the parent ions with $\mathrm{m} / \mathrm{z}=127$ and 60 are summarized in Table 4. The molecular formula listed in the last column of Table 4 refers to Table 2 and will be discussed in section 5. Two typical CID spectra are shown in Figure 4. CID experiments were performed with the collision gas pulse adjusted so that the parent ion intensity is reduced by $\sim 45 \%$. The CID fragmentation patterns are (in $\mathrm{m} / \mathrm{z}$ values) $127 \rightarrow 85$, $68,43,28,18$, and $60 \rightarrow 43,28$, and 18 .

\section{Analysis of Experimental Data}

5.1. Identifying the $1^{1} \mathrm{~A}^{\prime \prime}$ and $2^{1} \mathrm{~A}^{\prime}$ States. Calculated excitation energies are in agreement with the low-resolution absorption spectra of melamine. According to our calculation, the $1^{1} \mathrm{~A}^{\prime \prime} \leftarrow 1^{1} \mathrm{~A}^{\prime}$ excitation energy of melamine lies in the interval of 4.6-4.9 eV (269-253 nm). Neighboring this energy range, there exist three triplets, $1^{3} \mathrm{~A}^{\prime}(4.38 \pm 0.2 \mathrm{eV}), 1^{3} \mathrm{~A}^{\prime \prime}$ $(4.89 \mathrm{eV})$, and $2^{3} \mathrm{~A}^{\prime \prime}$ which is virtually degenerated with $2^{3} \mathrm{~A}^{\prime}$. Since the spectral transitions from the $1^{1} \mathrm{~A}^{\prime}$ ground state to these excited triplets are spin forbidden, the band with a peak at $\sim 275$ $\mathrm{nm}$ in the water/methanol $=3: 7$ mixture can be attributed to the $n-\pi^{*}$ transition of $1^{1} \mathrm{~A}^{\prime \prime} \leftarrow 1^{1} \mathrm{~A}^{\prime}$. The observed blue shift with increasing solvent polarity supports the assignment of this $n-\pi^{*}$ transition. With a $266 \mathrm{~nm}$ laser in our LDI experiment, we actually excite the melamine molecule to the $1^{1} \mathrm{~A}^{\prime \prime}$ excited state. 

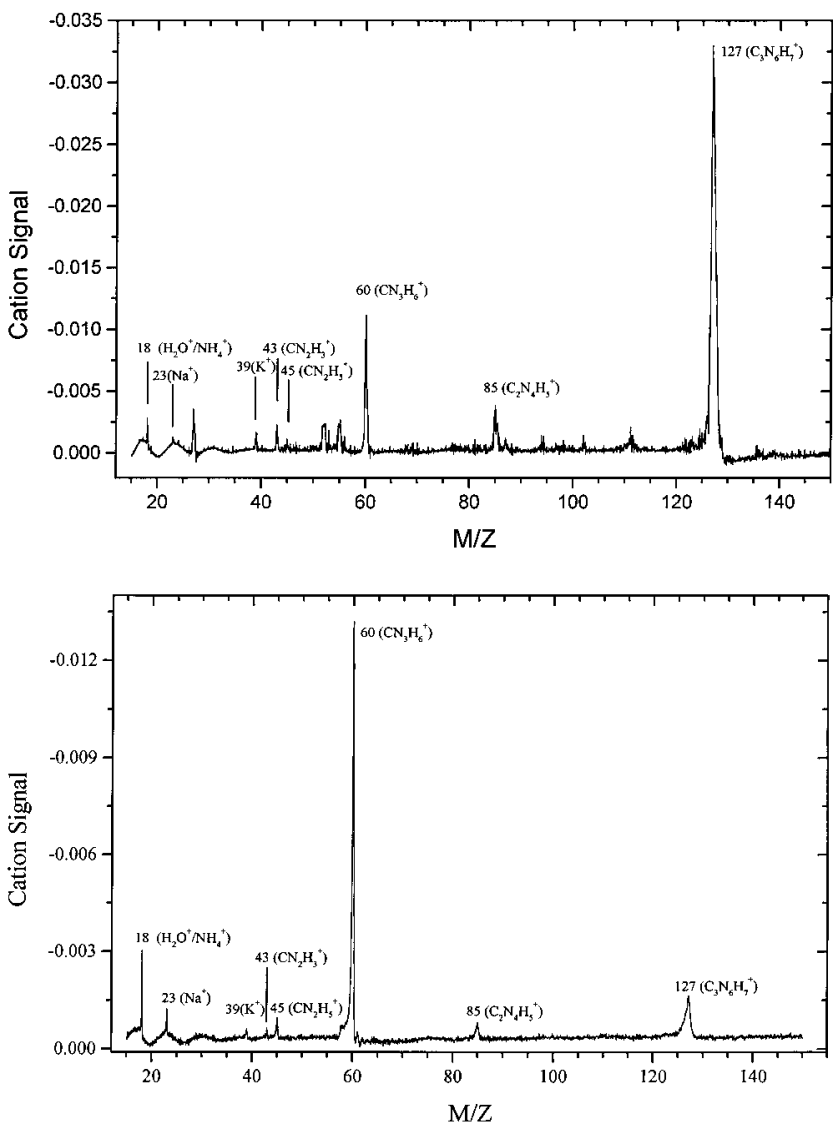

Figure 3. The laser-desorption ionization mass spectra of melamine under laser pumps of (a) $266 \mathrm{~nm}$ and (b) $193 \mathrm{~nm}$. The ion detections were delayed 19 and $9 \mu$ s, respectively, with respect to the LDI laser firing.

TABLE 3: Fragment Ions in the LDI Experiments of Melamine with 193 and $266 \mathrm{~nm}$ Lasers

\begin{tabular}{clcc}
\hline $\begin{array}{c}\text { melamine } \\
(\mathrm{m} / \mathrm{z} \text { value })\end{array}$ & $\begin{array}{c}\text { partially deuterated } \\
\text { melamine } \\
(\mathrm{m} / \mathrm{z} \text { value })\end{array}$ & $\begin{array}{c}\text { fully deuterated } \\
\text { melamine } \\
(\mathrm{m} / \mathrm{z} \text { value })\end{array}$ & $\begin{array}{c}\text { molecular } \\
\text { formula }\end{array}$ \\
\hline 43 & $43,44,45,46$ & 46 & $\mathrm{CN}_{2} \mathrm{H}_{3}{ }^{+}$ \\
45 & $45,46,47,48,49,50$ & 49,50 & $\mathrm{CN}_{2} \mathrm{H}_{5}{ }^{+}$ \\
60 & $60,61,62,63,64,65,66$ & $64,65,66$ & $\mathrm{CN}_{3} \mathrm{H}_{6}{ }^{+}$ \\
$(68)^{c}$ & $68,69,70$ & 70 & $\mathrm{C}_{2} \mathrm{~N}_{3} \mathrm{H}_{2}{ }^{+}$ \\
85 & $85,86,87,88,89,90$ & 89,90 & $\mathrm{C}_{2} \mathrm{~N}_{4} \mathrm{H}_{5}^{+}$ \\
$(110)^{c}$ & 110 & 114 & $\mathrm{C}_{3} \mathrm{~N}_{5} \mathrm{H}_{4}^{+}$ \\
127 & 127,133 & 133,134 & $\mathrm{C}_{3} \mathrm{~N}_{6} \mathrm{H}_{7}^{+}$
\end{tabular}

${ }^{a}$ Experiment with both 193 and 266 nm lasers. ${ }^{b}$ Experiment only with $193 \mathrm{~nm}$ laser. ${ }^{c} \mathrm{~m} / \mathrm{z}=68$ and 110 ions are not observed in the LDI of melamine (Figure 3), but they appear in that of partially deuterated melamine. See the text and ref 26.

The next singlet state $2^{1} \mathrm{~A}^{\prime}$ also has a mixed $\pi / n-\pi^{*}$ character with an estimated energy of $6.43 \mathrm{eV}(193 \mathrm{~nm})$. The oscillator strength for $2^{1} \mathrm{~A}^{\prime} \leftarrow 1^{1} \mathrm{~A}^{\prime}$ is significantly larger than that of $1^{1} \mathrm{~A}^{\prime \prime}$ $\leftarrow 1^{1} \mathrm{~A}^{\prime}$. The strong band at $200-240 \mathrm{~nm}$ is assigned to $2^{1} \mathrm{~A}^{\prime}$ $\leftarrow 1^{1} \mathrm{~A}^{\prime}$. We thus conclude that in our $193 \mathrm{~nm}$ LDI experiment the melamine molecule is pumped to the $2^{1} \mathrm{~A}^{\prime}$ state.

5.2. Chemical Formula of Fragment Ions. The chemical compositions of the fragment ions formed in the EI and LDI of melamine are revealed with the aid of their deuterated counterparts. Whenever there is one $\mathrm{H}$ atom being substituted by $\mathrm{D}$ atom in the fragment ion, the $\mathrm{m} / \mathrm{z}$ value increases by one. Therefore, the maximum increase in $\mathrm{m} / \mathrm{z}$ value found in the deuterated counterparts should indicate the number of $\mathrm{H}$ atoms contained in the fragment ion. Under this constraint, we are able to deduce the molecular formula for these fragment species.
TABLE 4: Daughter Ions Formed in the CID Experiments of the Parent Ions at $m / z=127$ and 60

\begin{tabular}{|c|c|c|c|c|c|}
\hline \multirow[b]{2}{*}{ species } & \multicolumn{2}{|c|}{$\mathrm{m} / \mathrm{z}$} & \multicolumn{2}{|c|}{ field strength } & \multirow{2}{*}{$\begin{array}{l}\text { molecular } \\
\text { formula }\end{array}$} \\
\hline & $M_{\mathrm{p}}$ & $M_{\mathrm{d}}$ & $V_{\mathrm{p}}$ & $V_{\mathrm{d}}$ & \\
\hline \multirow{7}{*}{$\begin{array}{l}\text { parent } \\
\text { daughter }\end{array}$} & 127 & & 3046 & & $\mathrm{C}_{3} \mathrm{~N}_{6} \mathrm{H}_{7}^{+}$ \\
\hline & & 84.85 & & 2035 & \\
\hline & & 68.29 & & 1638 & $\mathrm{C}_{2} \mathrm{~N}_{4} \mathrm{H}_{5}{ }^{+}$ \\
\hline & & 42.78 & & 1026 & $\mathrm{C}_{2} \mathrm{~N}_{3} \mathrm{H}_{2}{ }^{+}$ \\
\hline & & 28.0 & & 671 & $\mathrm{CN}_{2} \mathrm{H}_{3}^{+}$ \\
\hline & & 18.3 & & 438 & $\mathrm{CNH}_{2}^{+}$ \\
\hline & & & & & $\mathrm{NH}_{4}^{+}$ \\
\hline \multirow{4}{*}{ daughter } & 60 & & 3046 & & $\mathrm{CN}_{3} \mathrm{H}_{6}{ }^{+}$ \\
\hline & & 43.16 & & 2191 & \\
\hline & & 27.50 & & 1396 & $\mathrm{CN}_{2} \mathrm{H}_{3}{ }^{+}$ \\
\hline & & 17.7 & & 897 & $\begin{array}{l}\mathrm{CNH}_{2}^{+} \\
\mathrm{NH}_{4}^{+}\end{array}$ \\
\hline
\end{tabular}

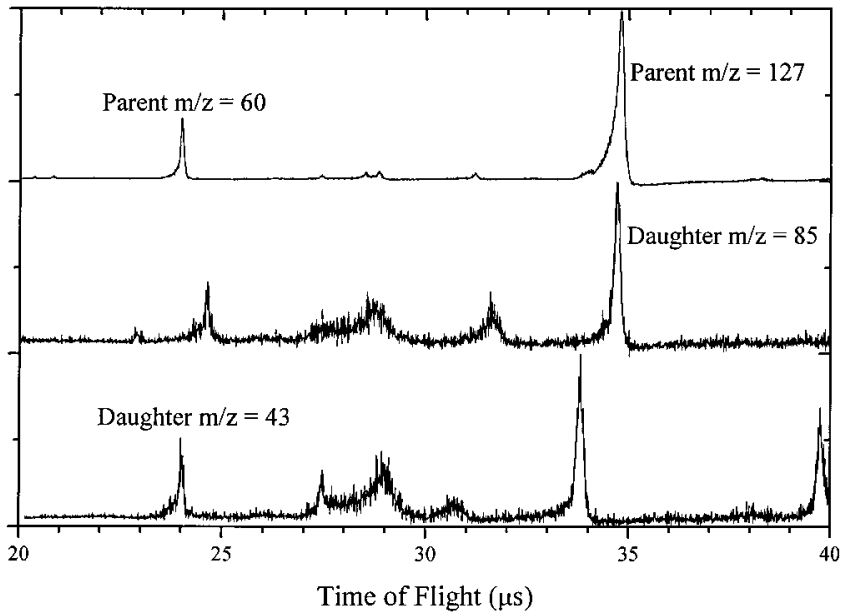

Figure 4. The upper trace shows that the parent ion spectrum recorded at full reflectron field strength, $V_{\mathrm{p}}=3046 \mathrm{~V}$, with the $\mathrm{m} / \mathrm{z}=127$ and 60 peaks located at $\mathrm{TOF}=34.6$ and $23.8 \mu \mathrm{s}$, respectively. The middle trace shows that the daughter-ion spectrum recorded at reduced reflectron voltage of $V_{\mathrm{d}}=2035 \mathrm{~V}$, the $\mathrm{m} / \mathrm{z}=85$ peak also appears at $\mathrm{TOF}=34.6 \mu \mathrm{s}$. The lower trace shows that the daughter ion spectrum at $V_{\mathrm{d}}=2191 \mathrm{~V}$, the $m / z=43$ peak appears at $\mathrm{TOF}=23.8 \mu \mathrm{s}$.

The results are listed in the last columns of Tables 2 and 3, and the proposed structures for these species are, for instance, protonated carbodiimide for $\mathrm{m} / \mathrm{z}=43$, formamidinium cation for $m / z=45$, protonated cyanogen for $m / z=53$, guanidinium cation for $m / z=60$, etc. The optimized structures for these ions with ab initio calculation and spectroscopic study of the structures and isomerization dynamics will be our continuing work.

In our EI and LDI experiments, abundant hydrogens are apparently available in the decomposition process of melamine which result in the observation of a few protonated fragmentary species. The source of the hydrogen atoms could be the cleavage of the $\mathrm{N}-\mathrm{H}$ bonds in the ground or electronically excited states of melamine. Also, one melamine molecule in excited electronic state may abstract a proton from another one to form a protonated parent ion.

5.3. Processes in EI: Ionization $\rightarrow$ Fragmentation. Our EI and LDI measurements show that the fragmentation of melamine in these experimental conditions is different from the photodissociation of s-triazine. If melamine undergoes the same concerted triple dissociation pathway as s-triazine does, then the sole products we observe in the mass spectrum would be carbodiimide ion $\left(\mathrm{m} / \mathrm{z}=42, \mathrm{CN}_{2} \mathrm{H}_{2}{ }^{+}\right)$or protonated carbodiimide $\left(\mathrm{m} / \mathrm{z}=43, \mathrm{CN}_{2} \mathrm{H}_{3}{ }^{+}\right)$. However, this is not the case; fragments with $\mathrm{m} / \mathrm{z}$ larger than 43 are observed. The presence 
of a prominent $\mathrm{m} / \mathrm{z}=60$ peak in LDI mass spectra, but its absence in EI indicate that the decomposition mechanisms in EI and LDI are quite different. In the EI experiment, melamine is probably ionized immediately by the energetic electrons to yield the parent molecular ion with $\mathrm{m} / \mathrm{z}=126$. This is supported by the strong signals of $\mathrm{m} / \mathrm{z}=126$ but weak $\mathrm{m} / \mathrm{z}=127$ in the EI experiment. All other fragment ions detected in the EI spectra are speculated to be daughter ions originating from the decomposition of parent molecular ion with $\mathrm{m} / \mathrm{z}=126$. This is supported by the CID results. When $\mathrm{m} / \mathrm{z}=127$ was collisionally activated, only $\mathrm{m} / \mathrm{z}=43,68$, and 85 were formed, but $\mathrm{m} / \mathrm{z}=$ 60 fragment ion was not observed. On the other hand, $m / z=$ 60 is one of the major fragments in the LDI of melamine.

Although, in our CID experiment, the parent ion of $\mathrm{m} / \mathrm{z}=$ 127 (protonated melamine) rather than 126 (melamine ion) was probed, we expect that the decomposition mechanism should be similar. We assume that the similarity in the decompositions of protonated melamine and melamine ion is due to the fact protonation does not dramatically vary the PES of the original neutral molecule, which is nearly the same as that of the corresponding molecular ion for large molecules.

Meanwhile, one cannot rule out that the difference between EI and LDI spectra may be in part due to the possible role of spin-forbidden (quartet) ionic states which can be populated in EI. To support this hypothesis, a study of the quartet PES for melamine ion is required.

5.4. Processes in LDI: Internal Conversion $\rightarrow$ Fragmentation $\rightarrow$ Ionization. According to our calculations, the excited singlet $1^{1} \mathrm{~A}^{\prime \prime}$ and triplet $1^{3} \mathrm{~A}^{\prime}$ are bound states with no apparent predissociative character, because stable minima are formed after geometry relaxation. The electronic structure of the $2^{1} \mathrm{~A}^{\prime}$ state differs from that of $1^{3} \mathrm{~A}^{\prime}$ only by spin direction of one of the electrons. Therefore, the structure of $2^{1} \mathrm{~A}^{\prime}$ should be similar to that of $1^{3} \mathrm{~A}^{\prime}$ and we expect that the former does not predissociate either. It is most likely that the photodissociation of melamine takes place along the ground PES after a radiationless transition from the excited-state potential by an internal conversion or at the point where the two surfaces cross. The internal conversion mechanism is also believed to be preferential in the photodecomposition of the simpler analogue of melamine, s-triazine. ${ }^{8-10}$ Ondrey and Bersohn ${ }^{8}$ made this conclusion based on the comparison of the energy available from photoexcitation at 248 and $193 \mathrm{~nm}$ with the electronic excitation energy of the HCN fragments. Osamura et al. ${ }^{10}$ investigated the possibility of the s-triazine photodissociation via electronically excited states by calculating the $n-\pi^{*}\left({ }^{1} \mathrm{~A}_{1}{ }^{\prime \prime}\right)$ and $\pi-\pi^{*}\left({ }^{1} \mathrm{~A}_{2}{ }^{\prime}\right)$ PES's. They found that the energies of these excited states increase along the dissociation path and these states correlate to the excited states of HCN which are energetically high. Therefore, they concluded that the radiationless transition has to occur to lead to the s-triazine $\rightarrow$ 3HCN dissociation.

A similar suggestion for melamine is supported by the LDI results with 266 and $193 \mathrm{~nm}$ laser pumps, where melamine is excited to the $1^{1} \mathrm{~A}^{\prime \prime}$ and $2^{1} \mathrm{~A}^{\prime}$ states, respectively. The same fragment ions, as shown in Table 3 , resulting from different excited electronic states $\left(1^{1} \mathrm{~A}^{\prime \prime}\right.$ and $\left.2^{1} \mathrm{~A}^{\prime}\right)$ of melamine are in line of reasoning the internal conversion to the ground potential prior to its dissociation. If an alternative mechanism with ionization preceding the fragmentation is preferable, the $\mathrm{m} / \mathrm{z}=$ 126 signal should be seen in the LDI spectra, which is not the case. However, a more thorough study of the PES of melamine for both the ground and excited states for photodissociation processes is needed to further clarify the detailed dissociation mechanism.
Density functional calculations for melamine fragmentation in the ground state reported in the next section support the internal conversion $\rightarrow$ fragmentation $\rightarrow$ ionization reaction mechanism for LDI, since the pathway leading to the $\mathrm{m} / \mathrm{z}=60$ product is the most favorable energetically. On the other hand, although the $m / z=126$ signal is absent in LDI, the mechanism involving multiphoton ionization followed by fragmentation cannot be completely ruled out. Further studies including photodissociation of melamine in the gas phase would be informative.

\section{Potential Energy Surface for Melamine Fragmentation}

6.1. Comparison of Melamine and s-Triazine. The optimized geometries of various intermediates of $\mathrm{C}_{3} \mathrm{~N}_{6} \mathrm{H}_{6}$ and its dissociation products are respectively presented in Figures $\mathrm{S} 1$ and S2 (Supporting Information), and their energies are collected in Table 5. It is known ${ }^{1,27-29}$ that the most stable isomer of melamine can exist in two conformations of $C_{s}$ and $C_{3 v}$ symmetry which have very close energies. Their difference is minor and is not relevant to the dissociation mechanism, so we consider below only one $C_{s}$ form (1a).

s-Triazine is known to decompose by a concerted triple dissociation mechanism forming the HCN products. ${ }^{8,9}$ Therefore, we first of all studied the similar mechanism for the melamine molecule. The transition state TS1 for the concerted dissociation of $\mathrm{C}_{3} \mathrm{~N}_{6} \mathrm{H}_{6}$ (1a) leading to $3 \mathrm{NCNH}_{2}$ is shown in Figure 5. Similar to the s-triazine case, ${ }^{10,24}$ TS1 has $C_{3}$ symmetry. The breaking $\mathrm{CN}$ bonds are elongated to $2.02 \AA$ and the $\mathrm{CN}$ bonds becoming triple in $\mathrm{N} \equiv \mathrm{C}-\mathrm{NH}_{2}$ are shortened to $1.19 \AA$. The geometry of the $\mathrm{C}_{3} \mathrm{~N}_{3}$ ring in TS1 is very close to that in the transition state for the concerted dissociation of s-triazine. The dissociation barrier at TS1 is calculated to be 110.0 and 104.8 $\mathrm{kcal} / \mathrm{mol}$ at the B3LYP level with the 6-31G* and cc-pVTZ basis sets, respectively. This value is significantly higher than the barrier for the dissociation of s-triazine, 86-94 kcal/mol at the QCISD(T) and B3LYP levels with various basis sets, in particular, $88.6 \mathrm{kcal} / \mathrm{mol}$ at B3LYP/cc-pVTZ. ${ }^{24}$ The difference in the barrier heights can be attributed to the difference in the endothermicities of the $\mathrm{C}_{3} \mathrm{~N}_{6} \mathrm{H}_{6}(\mathbf{1 a}) \rightarrow 3 \mathrm{NCNH}_{2}$ and $\mathrm{C}_{3} \mathrm{~N}_{3} \mathrm{H}_{3}$ $\rightarrow 3 \mathrm{HCN}$ reactions, 75.7 vs $48.8 \mathrm{kcal} / \mathrm{mol}$ at the $\mathrm{B} 3 \mathrm{LYP} / \mathrm{cc}-$ $\mathrm{pVTZ}$ level. For the s-triazine reaction, the B3LYP/cc-pVTZ computed reaction heat is close to the experimental value. ${ }^{24}$ The reverse barrier for the reaction of melamine $(29.1 \mathrm{kcal} / \mathrm{mol})$ is lower than that for s-triazine $(39.8 \mathrm{kcal} / \mathrm{mol})$. To our knowledge, no experimental thermodynamic data are available for the $\mathrm{C}_{3} \mathrm{~N}_{6} \mathrm{H}_{6} \mathbf{1 a} \rightarrow 3 \mathrm{NCNH}_{2}$ reaction.

Another possible mechanism of the s-triazine dissociation is a stepwise one: $\mathrm{C}_{3} \mathrm{~N}_{3} \mathrm{H}_{3} \rightarrow \mathrm{C}_{2} \mathrm{~N}_{2} \mathrm{H}_{2}+\mathrm{HCN} \rightarrow 3 \mathrm{HCN}$. Rice and co-workers ${ }^{24}$ found that the primary products on this pathway, $\mathrm{C}_{2} \mathrm{~N}_{2} \mathrm{H}_{2}+\mathrm{HCN}$, lie several $\mathrm{kcal} / \mathrm{mol}$ higher in energy than the transition state for the concerted triple dissociation and concluded that the stepwise mechanism is less favorable than the concerted one. For melamine, the endothermicity of the 1a $\rightarrow \mathrm{C}_{2} \mathrm{~N}_{4} \mathrm{H}_{4}(a)+\mathrm{NCNH}_{2}$ reaction is 91.6 and $86.4 \mathrm{kcal} / \mathrm{mol}$ with the $6-31 \mathrm{G}^{*}$ and cc-pVTZ basis sets, respectively, lower than the barrier for concerted dissociation. Therefore, we searched for a transition state corresponding to the $\mathrm{NCNH}_{2}$ elimination from melamine. The calculations result in TS2 and the barrier is very high, $140.9 \mathrm{kcal} / \mathrm{mol}$ at the B3LYP/6-31G* level. Thus, it seems that melamine should decompose in the concerted manner, similar to s-triazine, and the major dissociation product should be $\mathrm{NCNH}_{2}$.

However, this is not the case in experiment. Let us now consider what makes the melamine dissociation mechanism 
TABLE 5: Relative Energies (kcal/mol) of Various Isomers, Dissociation Products, and Transition States of Melamine, Calculated at the B3LYP/6-31G* and B3LYP/cc-pVTZ Levels of Theory

\begin{tabular}{|c|c|c|c|}
\hline species & $\mathrm{ZPE}^{a}$ & B3LYP/6-31G* & B3LYP/cc-pVTZ \\
\hline $\mathrm{C}_{3} \mathrm{~N}_{6} \mathrm{H}_{6}, \mathbf{1 a}^{b}$ & 73.4 & -446.49174 & -446.67036 \\
\hline $\mathrm{C}_{3} \mathrm{~N}_{6} \mathrm{H}_{6}, \mathbf{1 b}$ & 73.2 & 18.7 & \\
\hline $\mathrm{C}_{3} \mathrm{~N}_{6} \mathrm{H}_{6}, \mathbf{1 c}$ & 73.2 & 27.7 & \\
\hline $\mathrm{C}_{3} \mathrm{~N}_{6} \mathrm{H}_{6}, \mathbf{1 d}$ & 73.1 & 32.6 & \\
\hline $\mathrm{C}_{3} \mathrm{~N}_{6} \mathrm{H}_{6}, 1 \mathrm{e}$ & 71.3 & 59.5 & \\
\hline $\mathrm{C}_{3} \mathrm{~N}_{6} \mathrm{H}_{6}, \mathbf{1 f}$ & 71.4 & 48.3 & \\
\hline $\mathrm{C}_{3} \mathrm{~N}_{6} \mathrm{H}_{6}, \mathbf{1 g}$ & 71.3 & 52.2 & \\
\hline $\mathrm{C}_{3} \mathrm{~N}_{6} \mathrm{H}_{6}, \mathbf{l h}$ & 73.2 & 18.7 & \\
\hline $\mathrm{C}_{3} \mathrm{~N}_{6} \mathrm{H}_{6}, \mathbf{1 i}$ & 71.3 & 62.0 & \\
\hline $\mathrm{C}_{3} \mathrm{~N}_{6} \mathrm{H}_{6}, \mathbf{1} \mathbf{j}$ & 71.4 & 55.6 & \\
\hline $\mathrm{CN}_{3} \mathrm{H}_{5} \cdot \mathrm{C}_{2} \mathrm{~N}_{3} \mathrm{H}, \mathbf{1 k}$ & 68.7 & 56.8 & \\
\hline $\mathrm{C}_{3} \mathrm{~N}_{6} \mathrm{H}_{6}, \mathrm{ll}$ & 70.4 & 106.8 & \\
\hline $\mathrm{CN}_{3} \mathrm{H}_{5}+\mathrm{C}_{2} \mathrm{~N}_{3} \mathrm{H}$ & $47.9+20.1$ & 72.4 & 64.7 \\
\hline $3 \mathrm{NCNH}_{2}$ & $3(21.4)$ & 86.1 & 75.7 \\
\hline $3 \mathrm{HNCNH}$ & $3(20.5)$ & 86.5 & 71.9 \\
\hline $\mathrm{C}_{2} \mathrm{~N}_{4} \mathrm{H}_{4}(\mathbf{a})+\mathrm{NCNH}_{2}$ & $46.1+21.4$ & 91.6 & 86.4 \\
\hline $\mathrm{C}_{2} \mathrm{~N}_{4} \mathrm{H}_{4}(\mathbf{a})+\mathrm{HNCNH}$ & $46.1+20.5$ & 91.7 & 85.1 \\
\hline $\mathrm{C}_{2} \mathrm{~N}_{4} \mathrm{H}_{4}(\mathbf{b})+\mathrm{NCNH}_{2}$ & $47.2+21.4$ & 83.3 & \\
\hline $\mathrm{C}_{2} \mathrm{~N}_{4} \mathrm{H}_{4}(\mathbf{c})+\mathrm{NCNH}_{2}$ & $47.1+21.4$ & 78.4 & \\
\hline $\mathrm{C}_{2} \mathrm{~N}_{5} \mathrm{H}_{5}(\mathbf{a})+\mathrm{HNC}$ & $58.7+9.8$ & 76.6 & 72.0 \\
\hline $\mathrm{C}_{2} \mathrm{~N}_{5} \mathrm{H}_{5}(\mathbf{b})+\mathrm{HNC}$ & $58.5+9.8$ & 98.3 & \\
\hline $\mathrm{C}_{2} \mathrm{~N}_{5} \mathrm{H}_{5}(\mathbf{c})+\mathrm{HNC}$ & $58.4+9.8$ & 89.4 & \\
\hline $\mathrm{C}_{2} \mathrm{~N}_{5} \mathrm{H}_{5}(\mathbf{d})+\mathrm{HNC}$ & $58.1+9.8$ & 103.3 & \\
\hline $\mathrm{CN}_{3} \mathrm{H}_{3}(\mathbf{a})+\mathrm{C}_{2} \mathrm{~N}_{3} \mathrm{H}_{3}(\mathbf{a})$ & $31.9+34.3$ & 155.9 & \\
\hline $\mathrm{CN}_{3} \mathrm{H}_{3}(\mathbf{a})+\mathrm{C}_{2} \mathrm{~N}_{3} \mathrm{H}_{3}(\mathbf{b})$ & $31.9+35.0$ & 163.0 & \\
\hline $\mathrm{CN}_{3} \mathrm{H}_{3}(\mathbf{b})+\mathrm{C}_{2} \mathrm{~N}_{3} \mathrm{H}_{3}(\mathbf{a})$ & $32.3+34.3$ & 154.1 & \\
\hline $\mathrm{CN}_{3} \mathrm{H}_{3}(\mathbf{c})+\mathrm{C}_{2} \mathrm{~N}_{3} \mathrm{H}_{3}(\mathbf{a})$ & $31.9+34.3$ & 159.9 & \\
\hline $\mathrm{C}_{3} \mathrm{~N}_{5} \mathrm{H}_{5}(\mathbf{a})+{ }^{3} \mathrm{NH}$ & $61.3+4.6$ & 142.9 & \\
\hline $\mathrm{C}_{3} \mathrm{~N}_{5} \mathrm{H}_{5}(\mathbf{b})+{ }^{3} \mathrm{NH}$ & $61.8+4.6$ & 110.6 & \\
\hline $\mathrm{CN}_{2} \mathrm{H}_{4}(\mathbf{a})+\mathrm{C}_{2} \mathrm{~N}_{4} \mathrm{H}_{2}$ & $36.5+30.7$ & 134.1 & \\
\hline $\mathrm{CN}_{2} \mathrm{H}_{4}(\mathbf{b})+\mathrm{C}_{2} \mathrm{~N}_{4} \mathrm{H}_{2}$ & $35.9+30.7$ & 158.5 & \\
\hline TS1 & 68.0 & 110.0 & 104.8 \\
\hline TS2 & 69.6 & 140.9 & \\
\hline TS3 & 69.4 & 47.7 & \\
\hline TS4 & 69.4 & 62.3 & \\
\hline TS5 & 69.3 & 70.5 & \\
\hline TS6 & 69.0 & 96.4 & 93.6 \\
\hline TS7 & 68.3 & 51.5 & \\
\hline TS8 & 69.2 & 110.6 & 108.6 \\
\hline TS9 & 68.3 & 95.4 & \\
\hline TS10 & 69.2 & 71.8 & \\
\hline TS11 & 67.3 & 119.8 & \\
\hline TS12 & 66.7 & 125.2 & \\
\hline TS13 & 67.8 & 122.6 & \\
\hline TS14 & 67.3 & 128.3 & \\
\hline TS15 & 70.4 & 107.1 & 105.6 \\
\hline TS16 & 69.2 & 123.6 & \\
\hline TS17 & 69.2 & 124.8 & \\
\hline TS18 & 69.8 & 119.9 & \\
\hline TS19 & 68.6 & 134.6 & \\
\hline TS20 & 69.3 & 138.8 & \\
\hline TS21 & 68.8 & 144.6 & \\
\hline TS22 & 69.4 & 146.1 & \\
\hline TS23 & 66.7 & 154.3 & \\
\hline TS24 & 64.5 & 157.1 & \\
\hline TS25 & 68.5 & 133.0 & \\
\hline
\end{tabular}

${ }^{a}$ Zero-point energy corrections $(\mathrm{kcal} / \mathrm{mol})$, calculated at the B3LYP/6-31G* level. ${ }^{b}$ Total energies in hartrees. Relative energies for the other species are given with respect to $\mathbf{1 a}$.

different. Melamine has three out-of-ring amino groups and the $\mathrm{NH}_{2}$ hydrogens can exhibit a mobility, i.e., they can be shifted to the nitrogens of the $\mathrm{C}_{3} \mathrm{~N}_{3}$ ring to enhance the decomposition process. For instance, the first hydrogen shift destroys aromaticity of the melamine molecule:

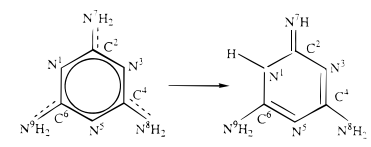

In melamine (structure 1a), all nine $\mathrm{CN}$ bonds have similar lengths, $1.34-1.36 \AA$, and the aromatic $\pi$ system involves all carbon and nitrogen atoms. After the hydrogen shifts isomer $\mathbf{1 b}$ is formed and a bond alteration occurs. The $\mathrm{C}^{2} \mathrm{~N},{ }^{7} \mathrm{~N}^{3} \mathrm{C},{ }^{4}$ and $\mathrm{N}^{5} \mathrm{C}^{6}$ bonds acquire a double-bond character with the bond lengths of $1.28-1.32 \AA$, while the other six $\mathrm{CN}$ bonds are rather single bonds, $1.35-1.42 \AA$. Some delocalization of the $\pi$ electrons apparently is still present in $\mathbf{1 b}$; the $\mathrm{N}^{1} \mathrm{C}^{6}$ bond $(1.35$ $\AA$ ) is too short for a regular single $\mathrm{CN}$ bond and the $\mathrm{N}^{3} \mathrm{C}^{4}$ and $\mathrm{N}^{5} \mathrm{C}^{6}$ double bonds are too long. The loss of aromaticity in $\mathbf{1 b}$ results in the energy loss; $\mathbf{1 b}$ is $18.7 \mathrm{kcal} / \mathrm{mol}$ less stable than 1a at the B3LYP/6-31G* level. The barrier for the hydrogen shift which occurs via TS3 (shown in Figure 6) is relatively low, $47.7 \mathrm{kcal} / \mathrm{mol}$. 


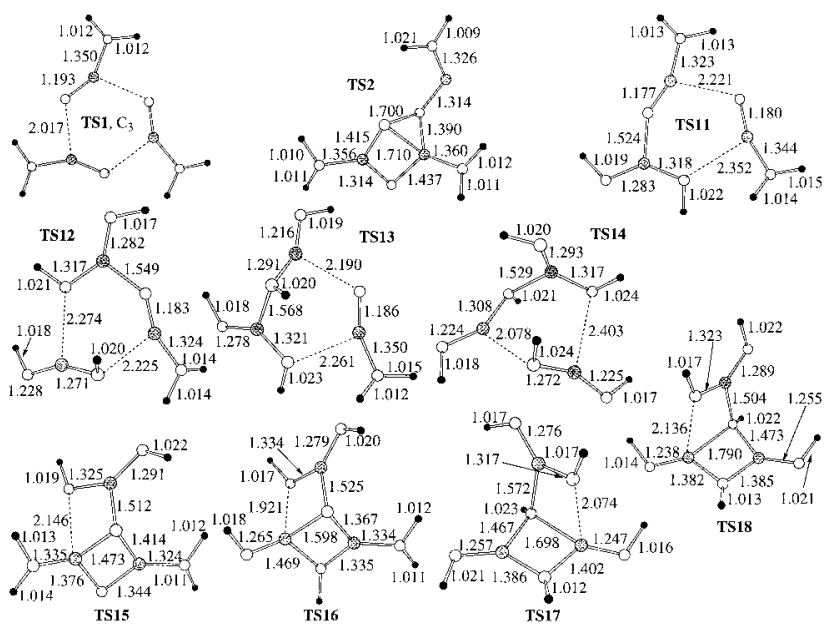

Figure 5. Optimized geometries (bond lengths in angstroms) of transition states for the concerted (TS1) and stepwise (TS2) dissociation of melamine and other transition states for the $\mathrm{C}_{3} \mathrm{~N}_{6} \mathrm{H}_{6} \rightarrow 3 \mathrm{CN}_{2} \mathrm{H}_{2}$ and $\mathrm{C}_{3} \mathrm{~N}_{6} \mathrm{H}_{6} \rightarrow \mathrm{C}_{2} \mathrm{~N}_{4} \mathrm{H}_{4}+\mathrm{CN}_{2} \mathrm{H}_{2}$ dissociation channels.
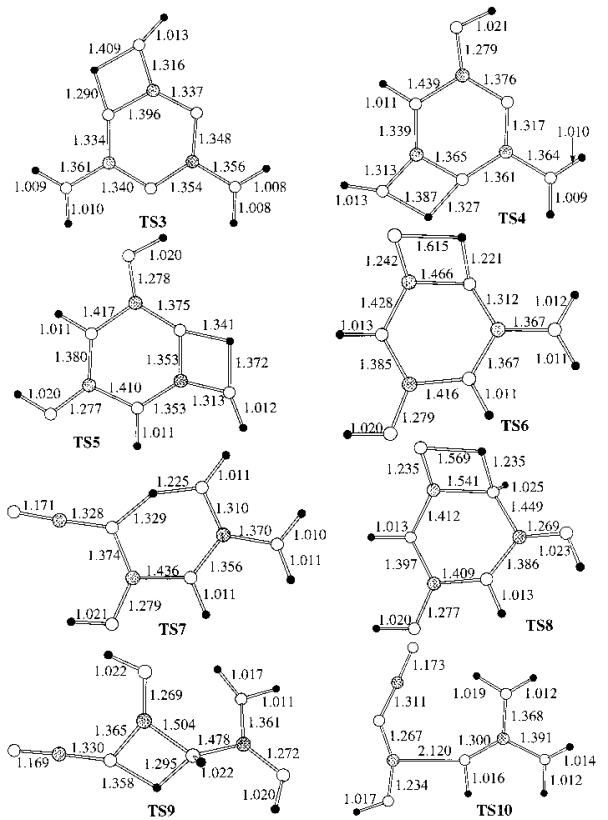

Figure 6. Optimized geometries (bond lengths in angstroms) of the hydrogen shift transition states.

The hydrogen shifts from the out-of-ring $\mathrm{NH}_{2}$ groups to the nitrogens of the ring can further continue: $\mathbf{1 a} \rightarrow \mathbf{T S 3} \rightarrow \mathbf{1 b} \rightarrow$ TS4 $\rightarrow$ 1c $\rightarrow$ TS5 $\rightarrow$ 1d. Three sequential hydrogen shifts lead to isomer $1 d$ which has all six single $\mathrm{CN}$ bonds $(1.39 \AA)$ in the $\mathrm{C}_{3} \mathrm{~N}_{3}$ ring and three out-of-ring double $\mathrm{CN}$ bonds $(1.28 \AA$ ):

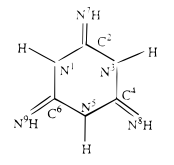

The stability of the $\mathrm{C}_{3} \mathrm{~N}_{6} \mathrm{H}_{6}$ isomers decreases in the row from 1a to $\mathbf{1 b}, \mathbf{1 c}$, and 1d. 1c and 1d lie 27.7 and $32.6 \mathrm{kcal} / \mathrm{mol}$ higher in energy than melamine, respectively. The energy required for the hydrogen shift to take place also increases; TS4 and TS5 lie 62.3 and $70.5 \mathrm{kcal} / \mathrm{mol}$ above $1 \mathrm{a}$. All three transition states for the 1,3-hydrogen shift, TS3, TS4, and TS5, have similar structures and are closer to those of the products.

6.2. Formation of the $\mathbf{C N}_{3} \mathbf{H}_{5}+\mathbf{C}_{2} \mathbf{N}_{\mathbf{3}} \mathbf{H}$ Products. The $\mathrm{CN}_{3} \mathrm{H}_{5}+\mathrm{C}_{2} \mathrm{~N}_{3} \mathrm{H}$ dissociation products can be formed by two mechanisms involving the series of sequential hydrogen shifts. The profiles of PES for these mechanisms are shown in Figure 7 , and the most favorable pathway is illustrated in Figure 8. After isomer 1c is formed by two hydrogen shifts from $\mathrm{N}^{7}$ to $\mathrm{N}^{1}$ and from $\mathrm{N}^{9}$ to $\mathrm{N},{ }^{5}$ the next hydrogen shift can again take place from the $\mathrm{N}^{7}$ atom connected to only one hydrogen. The $\mathrm{H}$ shift from $\mathrm{N}^{7}$ to $\mathrm{N}^{3}$ leads to the cleavage of the $\mathrm{C}^{2} \mathrm{~N}^{3}$ single bond and the formation of the $\mathrm{C}^{2} \mathrm{~N}^{7}$ triple bond in isomer $1 \mathrm{e}$. Isomer 1e lies $59.5 \mathrm{kcal} / \mathrm{mol}$ higher than melamine 1a. The reaction occurs via transition state TS6 and the calculated barrier is 96.4 and $93.6 \mathrm{kcal} / \mathrm{mol}$ at the B3LYP/6-31G* and B3LYP/ cc-pVTZ levels, respectively. At our best level, the barrier at TS6 is $11.2 \mathrm{kcal} / \mathrm{mol}$ lower than the barrier for the concerted triple dissociation of melamine. After $\mathbf{1 e}$, the reaction proceeds by a rotation around the single $\mathrm{C}^{1} \mathrm{~N}^{6}$ bond resulting in structure 1f. Since the rotation takes place around a single bond, the barrier is not expected to be high and we did not search for the corresponding transition state. 1f is $48.3 \mathrm{kcal} / \mathrm{mol}$ higher in energy than 1a but $11.2 \mathrm{kcal} / \mathrm{mol}$ lower than 1e. Isomer $\mathbf{1 f}$ is additionally stabilized by the intramolecular hydrogen bonding between the $\mathrm{H}$ atom connected to $\mathrm{N}^{1}$ and $\mathrm{N}^{3}$. The $\mathrm{N}^{1} \mathrm{H} \cdots \mathrm{N}^{3}$ distance is as short as $1.79 \AA$. The next reaction step is the 1,5-H shift from $\mathrm{N}^{1}$ to $\mathrm{N}^{3}$ to form $1 \mathrm{~g}$ via TS7. The barrier is very low, 3.2 and $51.5 \mathrm{kcal} / \mathrm{mol}$ relative to $\mathbf{1 f}$ and 1a, respectively. With ZPE corrections, $\mathbf{1 g}$ is slightly higher in energy than transition state TS7 separating it from 1f. However, on PES without ZPE $1 \mathrm{~g}$ lies $2.3 \mathrm{kcal} / \mathrm{mol}$ lower than TS7. The electronic structure of $\mathbf{1 g}$ can be described in terms of the following resonance structures

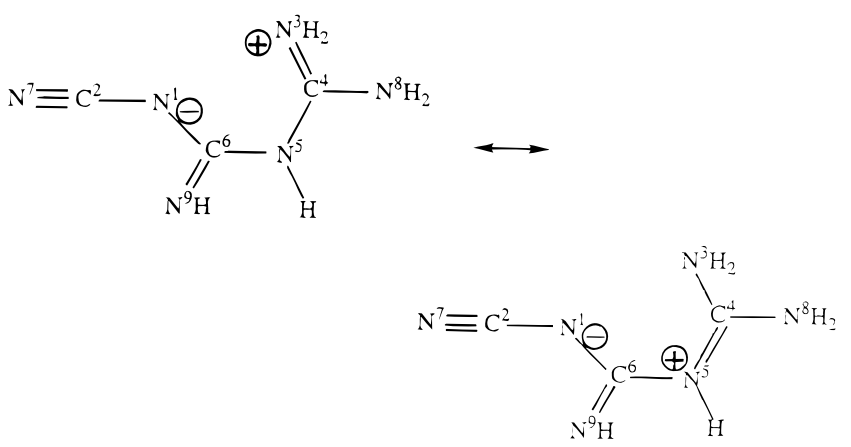

so the negative charge is accumulated on $\mathrm{N}^{1}$ and the positive charge is delocalized between $\mathrm{N}^{3}$ and N. $\mathbf{1 g}$ also has an intramolecular hydrogen bond between the $\mathrm{H}$ of $\mathrm{N}^{3}$ and $\mathrm{N}^{1}$ with the distance of $1.74 \AA$. Structure $1 \mathrm{~g}$ breaks apart by the cleavage of the single $\mathrm{N}^{5} \mathrm{C}^{6}$ bond giving the $\mathrm{CN}_{3} \mathrm{H}_{5}+\mathrm{NCNCNH}$ products via TS10. The energy of TS10, $71.8 \mathrm{kcal} / \mathrm{mol}$ relative to melamine, is $0.6 \mathrm{kcal} / \mathrm{mol}$ lower than that of the products at the B3LYP/6-31G* level. This indicates that $\mathrm{CN}_{3} \mathrm{H}_{5}$ and NCNCNH can form a hydrogen-bonded complex which is directly connected to the transition state. Indeed, such a complex $1 \mathbf{k}$ is calculated to lie $15.6 \mathrm{kcal} / \mathrm{mol}$ below $\mathrm{CN}_{3} \mathrm{H}_{5}+\mathrm{NCNCNH}$. It has a strong hydrogen bond between $\mathrm{N}^{5}$ and the $\mathrm{H}$ atom connected to N. ${ }^{9}$ At the B3LYP/cc-pVTZ level the overall endothermicity of the $\mathbf{1 a} \rightarrow \mathrm{CN}_{3} \mathrm{H}_{5}+\mathrm{NCNCNH}$ reaction is $64.7 \mathrm{kcal} / \mathrm{mol}$. Thus, this product channel is less endothermic than those leading to $3 \mathrm{NCNH}_{2}$ and $\mathrm{C}_{2} \mathrm{~N}_{4} \mathrm{H}_{4}+\mathrm{NCNH}_{2}$ by 11.0 and $21.7 \mathrm{kcal} / \mathrm{mol}$, respectively.

The described above pathway leading from melamine to $\mathrm{CN}_{3} \mathrm{H}_{5}+\mathrm{NCNCNH}$ consists of six steps, four of those are 1,3or 1,5-hydrogen shifts. The rate-determining step is the $\mathrm{H}$ shift between 1c and 1e accompanied with the ring opening and the corresponding transition state TS6 is $93.6 \mathrm{kcal} / \mathrm{mol}$ higher than 


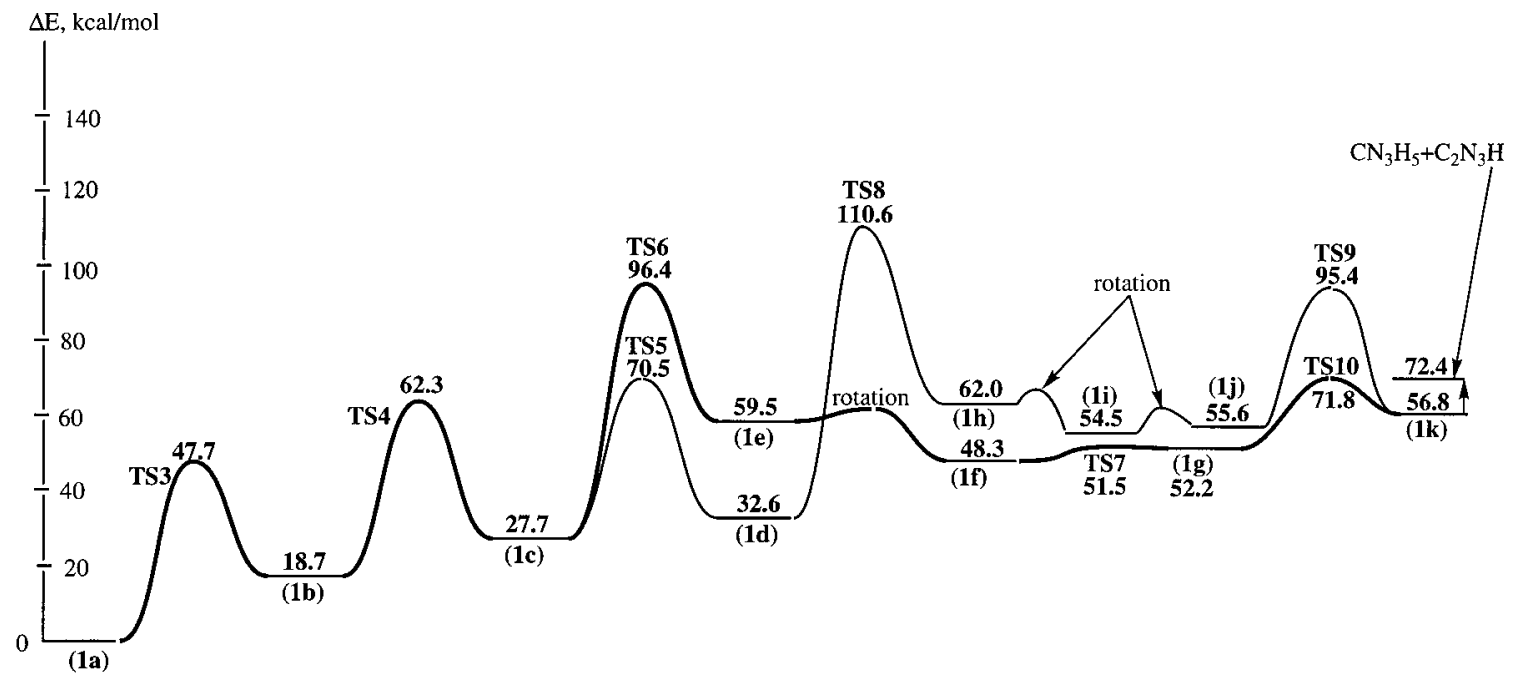

Figure 7. Potential energy surface of the $\mathrm{C}_{3} \mathrm{~N}_{6} \mathrm{H}_{6} \rightarrow \mathrm{CN}_{3} \mathrm{H}_{5}+\mathrm{C}_{2} \mathrm{~N}_{3} \mathrm{H}$ dissociation channel, calculated at the B3LYP/6-31G* level.

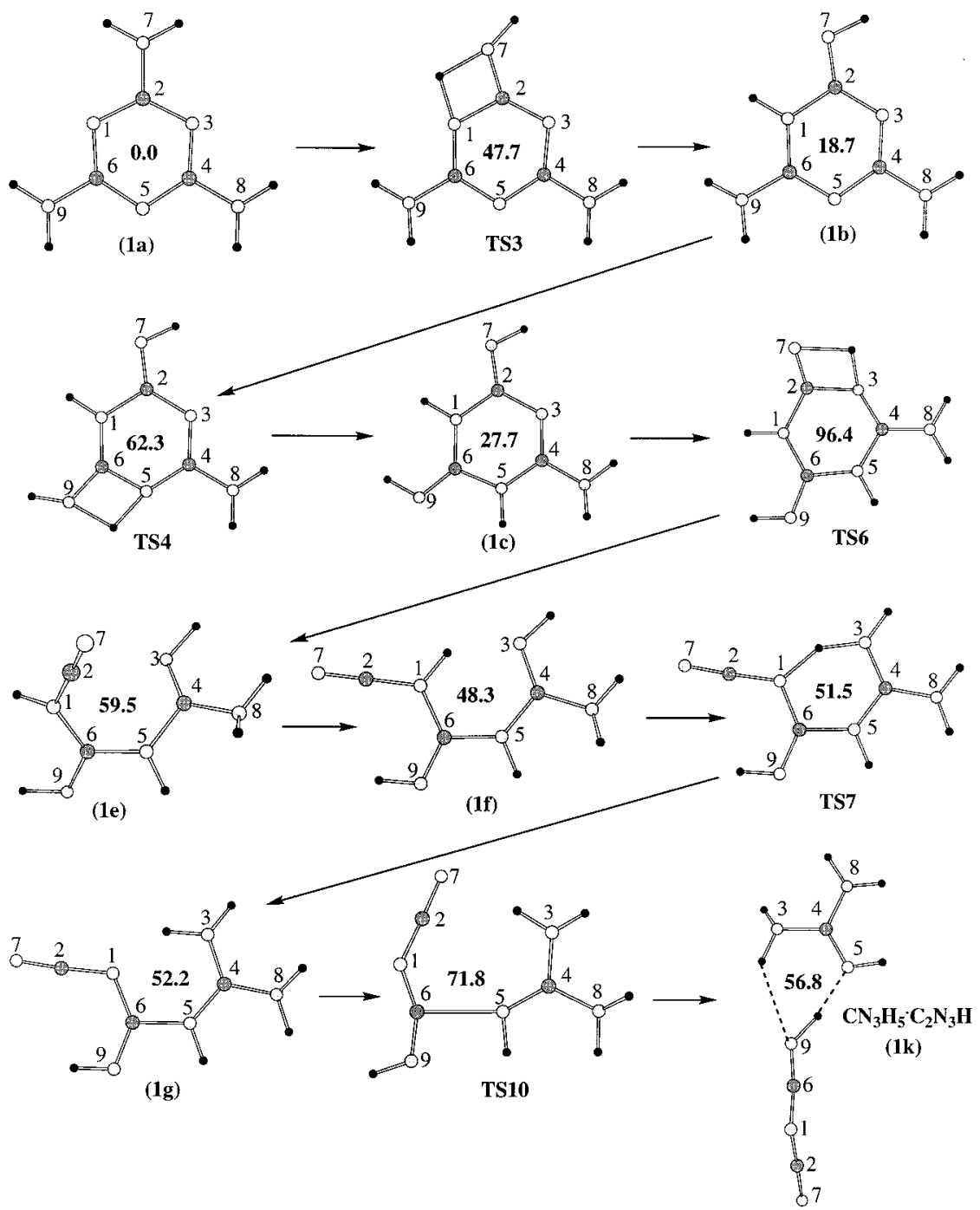

Figure 8. The most favorable pathway of the $\mathrm{C}_{3} \mathrm{~N}_{6} \mathrm{H}_{6} \rightarrow \mathrm{CN}_{3} \mathrm{H}_{5}+\mathrm{C}_{2} \mathrm{~N}_{3} \mathrm{H}$ dissociation channel. Bold number show relative energies for each structure with respect to $1 \mathrm{a}$, calculated at the B3LYP/6-31G* level.

melamine at our best B3LYP/cc-pVTZ level. Another mechanism leading to the same products is also possible though less favorable. As shown in Figure 9, the branching from the first pathway occurs at 1c. Instead of going via TS6, the third hydrogen shift takes place from $\mathrm{N}^{8}$ to $\mathrm{N}^{3}$ via TS5 leading to 1d. Only after that, the ring opens up by the hydrogen shift from $\mathrm{N}^{7}$ to $\mathrm{N}^{3}$. This step proceeds via $\mathbf{T S 8}$ and leads to the structure $\mathbf{1 h}$. The barrier for the ring opening is high; TS8 lies 110.6 and $108.6 \mathrm{kcal} / \mathrm{mol}$ higher in energy than the global minimum 1a at the B3LYP/6-31G* and B3LYP/cc-pVTZ levels, 


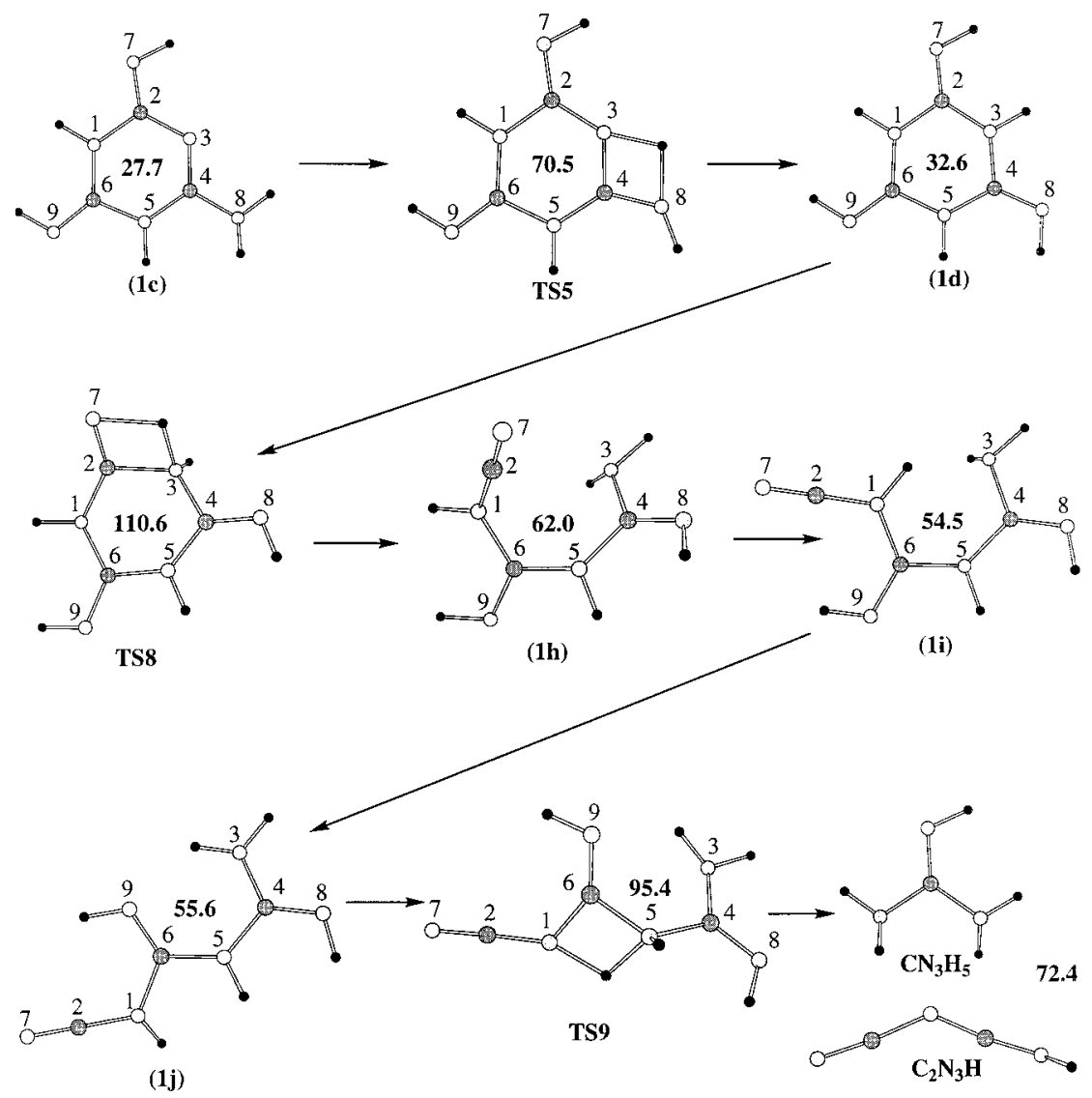

Figure 9. An alternative pathway of the $\mathrm{C}_{3} \mathrm{~N}_{6} \mathrm{H}_{6} \rightarrow \mathrm{CN}_{3} \mathrm{H}_{5}+\mathrm{C}_{2} \mathrm{~N}_{3} \mathrm{H}$ dissociation channel. Bold numbers show relative energies for each structure with respect to 1a, calculated at the B3LYP/6-31G* level.

respectively. The four hydrogen shifts from $\mathbf{1 a}$ to $\mathbf{1 h}$ are followed by two rotations about single bonds. The first rotation takes place around the $\mathrm{N}^{1} \mathrm{C}^{6}$ bond giving 1 i. The second rotation leading to $\mathbf{1 j}$ occurs around $\mathrm{N}^{5} \mathrm{C} .^{6}$ The relative energies of the $\mathbf{1 h}, \mathbf{1} \mathbf{i}$, and $\mathbf{1 j}$ open structures with regard to melamine are 62.0 , 54.5 , and $55.6 \mathrm{kcal} / \mathrm{mol}$, respectively. The rotations are expected to have low barriers and are not significant for the overall reaction rate. The final step is another 1,3-hydrogen shift in $\mathbf{1 j}$ from $\mathrm{N}^{1}$ to $\mathrm{N}^{5}$ which is accompanied by the cleavage of the $\mathrm{N}^{5} \mathrm{C}^{6}$ bond producing $\mathrm{CN}_{3} \mathrm{H}_{5}+\mathrm{NCNCNH}$. The barrier at the corresponding TS9 is about $15 \mathrm{kcal} / \mathrm{mol}$ lower than that at TS8, so the ring opening remains the rate-determining step. Overall, the reaction mechanism leading to $\mathrm{CN}_{3} \mathrm{H}_{5}+\mathrm{NCNCNH}$ via $1 d$ contains seven steps including five hydrogen shifts. The mechanism shown in Figure 9 is less favorable than that shown in Figure 8, because TS8 for the ring opening is $15.0 \mathrm{kcal} / \mathrm{mol}$ higher in energy than TS6.

6.3. Dissociation Mechanisms Leading to $3 \mathrm{CN}_{2} \mathrm{H}_{2}$ and $\mathbf{C}_{2} \mathbf{N}_{4} \mathbf{H}_{4}+\mathbf{C N}_{2} \mathbf{H}_{2}$. At this point we return to the dissociation mechanisms producing $3 \mathrm{CN}_{2} \mathrm{H}_{2}$ in the concerted manner and $\mathrm{C}_{2} \mathrm{~N}_{4} \mathrm{H}_{4}+\mathrm{CN}_{2} \mathrm{H}_{4}$ and consider how the activation energies are affected by hydrogen shifts. PES for the formation of $3 \mathrm{CN}_{2} \mathrm{H}_{2}$ is shown in Figure 10a and the corresponding transition states are drawn in Figure 5. Isomer $\mathbf{1 b}$ decomposes to $2 \mathrm{NCNH}_{2}+$ HNCNH via TS11 with the barrier of $119.8 \mathrm{kcal} / \mathrm{mol}$ at the B3LYP/6-31G* level. Thus, the barrier for the triple concerted mechanism increases by about $10 \mathrm{kcal} / \mathrm{mol}$ after the first hydrogen shift. The second and the third hydrogen shifts render the concerted dissociation even less probable. Isomer 1c can decompose to $\mathrm{NCNH}_{2}+2 \mathrm{HNCNH}$ through TS12 and TS13 with the barriers of 125.2 and $122.6 \mathrm{kcal} / \mathrm{mol}$, respectively. 1d dissociates to $3 \mathrm{HNCNH}$ via TS14 and the barrier is $128.3 \mathrm{kcal} /$ mol. Contrary to TS1 which has $C_{3}$ symmetry, transition states TS11-TS14 are not symmetric. Two isomers of the $\mathrm{CN}_{2} \mathrm{H}_{2}$ species can be produced in the dissociation of melamine, $C_{\mathrm{s}^{-}}$ symmetric $\mathrm{NCNH}_{2}$, and $C_{2}$-symmetric $\mathrm{HNCNH}$. At the B3LYP/ 6-31G* level, $\mathrm{HNCNH}$ is $0.1 \mathrm{kcal} / \mathrm{mol}$ more stable than $\mathrm{NCNH}_{2}$. However, B3LYP/cc-pVTZ gives $\mathrm{NCNH}_{2}$ to be $1.3 \mathrm{kcal} / \mathrm{mol}$ lower in energy than HNCNH. We can conclude that the two structures are close in energy. Higher level calculations for this small species can be performed but this is not within the goals of the present study. At the B3LYP/cc-pVTZ level, the endothermicity of the concerted $\mathrm{C}_{3} \mathrm{~N}_{6} \mathrm{H}_{6} \rightarrow 3 \mathrm{CN}_{2} \mathrm{H}_{2}$ dissociation varies in the $71.9-75.7 \mathrm{kcal} / \mathrm{mol}$ range.

PES for the $\mathrm{C}_{2} \mathrm{~N}_{4} \mathrm{H}_{4}+\mathrm{CN}_{2} \mathrm{H}_{2}$ dissociation channel is presented in Figure $10 \mathrm{~b}$ and the transition states are shown in Figure 5. The hydrogen shifts in melamine significantly enhance this reaction channel. Isomer $\mathbf{1 b}$ formed after the first $\mathrm{H}$ shift dissociates to $\mathrm{C}_{2} \mathrm{~N}_{4} \mathrm{H}_{4}$ (a) $+\mathrm{HNCNH}$ via TS15. The barrier is found to be 107.1 and $105.6 \mathrm{kcal} / \mathrm{mol}$ with the $6-31 \mathrm{G}^{*}$ and $\mathrm{cc}-$ pVTZ basis sets, respectively. Thus, the hydrogen shift decreases the barrier for the $\mathrm{C}_{3} \mathrm{~N}_{6} \mathrm{H}_{6} \rightarrow \mathrm{C}_{2} \mathrm{~N}_{4} \mathrm{H}_{4}+\mathrm{CN}_{2} \mathrm{H}_{2}$ reaction by more than $30 \mathrm{kcal} / \mathrm{mol}$. This dramatic result can be attributed to the fact that the $\mathrm{H}$ shift violates the aromatic system and the two $\mathrm{CN}$ bonds being broken in $\mathbf{1 b}$ during dissociation are single bonds. At the B3LYP/6-31G* level, the $\mathbf{1 a} \rightarrow \mathbf{T S 3} \rightarrow \mathbf{1 b} \rightarrow$ TS15 $\rightarrow \mathrm{C}_{2} \mathrm{~N}_{4} \mathrm{H}_{4}(\mathbf{a})+\mathrm{HNCNH}$ pathway has the activation energy of $\sim 3 \mathrm{kcal} / \mathrm{mol}$ lower than that for $\mathbf{1 a} \rightarrow \mathbf{T S 1} \rightarrow$ $3 \mathrm{NCNH}_{2}$. On the other hand, at the B3LYP/cc-pVTZ level, the barrier for the latter is slightly lower than that for the former. The two channels can compete with each other during the decomposition process, although both of them are less favorable than the mechanism of sequential hydrogen shifts leading to $\mathrm{CN}_{3} \mathrm{H}_{5}+\mathrm{NCNCNH}$. The heat of the $\mathbf{1 a} \rightarrow \mathrm{C}_{2} \mathrm{~N}_{4} \mathrm{H}_{4}$ (a) + 

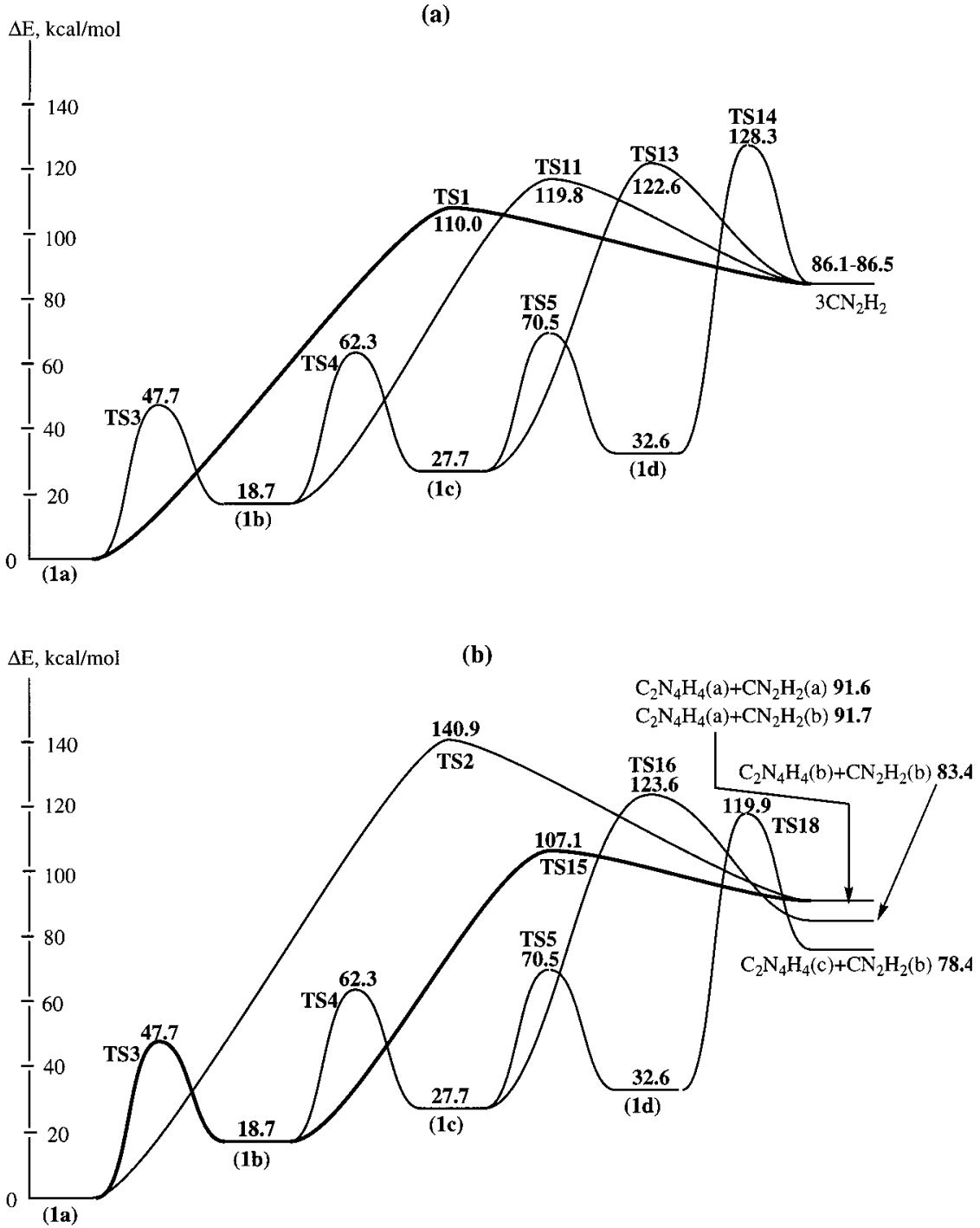

Figure 10. Potential energy surfaces of the $\mathrm{C}_{3} \mathrm{~N}_{6} \mathrm{H}_{6} \rightarrow 3 \mathrm{CN}_{2} \mathrm{H}_{2}$ (a) and $\mathrm{C}_{3} \mathrm{~N}_{6} \mathrm{H}_{6} \rightarrow \mathrm{C}_{2} \mathrm{~N}_{4} \mathrm{H}_{4}+\mathrm{CN}_{2} \mathrm{H}_{2}$ (b) dissociation channels, calculated at the B3LYP/6-31G* level.

$\mathrm{HNCNH}$ reaction is found to be 91.7 and $85.1 \mathrm{kcal} / \mathrm{mol}$ at the B3LYP/6-31G* and B3LYP/cc-pVTZ levels, respectively.

After the second hydrogen shift, decomposition of 1c can proceed via TS16 leading to $\mathrm{C}_{2} \mathrm{~N}_{4} \mathrm{H}_{4}$ (b) $+\mathrm{HNCNH}$. However, the barrier, $123.6 \mathrm{kcal} / \mathrm{mol}$ at $\mathrm{B} 3 \mathrm{LYP} / 6-31 \mathrm{G}^{*}$, is much higher than that at TS15. Finally, 1d dissociates to $\mathrm{C}_{2} \mathrm{~N}_{4} \mathrm{H}_{4}$ (c) + HNCNH via TS17 or TS18 with the barriers of 124.8 and 119.9 $\mathrm{kcal} / \mathrm{mol}$, respectively. Three isomers of the $\mathrm{C}_{2} \mathrm{~N}_{4} \mathrm{H}_{4}$ species can be produced: a, b, and c. $\mathrm{C}_{2} \mathrm{~N}_{4} \mathrm{H}_{4}$ (a) has two amino groups out of the $\mathrm{C}_{2} \mathrm{~N}_{4}$ aromatic ring. In structure $\mathbf{b}$ one $\mathrm{H}$ atom is shifted to a ring nitrogen and in $\mathbf{c}$ each nitrogen atom is connected to a hydrogen. At the B3LYP/6-31G* level, structure $\mathbf{c}$ is the most stable of the three, while $\mathbf{b}$ and $\mathbf{a}$ lie 4.9 and 13.2 $\mathrm{kcal} / \mathrm{mol}$ higher in energy, respectively. Higher level calculations would be required in order to confirm this result. Although the $\mathrm{C}_{2} \mathrm{~N}_{4} \mathrm{H}_{4}$ (a) structure is the least stable, this isomer is the most likely to be formed in melamine decomposition because of the lowest barrier at TS15.

6.4. Minor Dissociation Channels. Besides the major dissociation products such as $\mathrm{CN}_{3} \mathrm{H}_{5}, \mathrm{C}_{2} \mathrm{~N}_{4} \mathrm{H}_{4}$, and $\mathrm{CN}_{2} \mathrm{H}_{2}$, a group of minor products was also observed in the LDI and EI experiments. In this section, we consider decomposition pathways which can lead to these minor products. The $\mathrm{C}_{2} \mathrm{~N}_{5} \mathrm{H}_{5}{ }^{+}$ ion $(m / z=99)$ can be formed by ionization of $\mathrm{C}_{2} \mathrm{~N}_{5} \mathrm{H}_{5}$ which, in turn, is produced by $\mathrm{HNC}$ elimination from $\mathrm{C}_{3} \mathrm{~N}_{6} \mathrm{H}_{6}$. Figure 11a shows PES for the $\mathrm{C}_{3} \mathrm{~N}_{6} \mathrm{H}_{6} \rightarrow \mathrm{C}_{2} \mathrm{~N}_{5} \mathrm{H}_{5}+\mathrm{HNC}$ reaction and the corresponding transition states are presented in Figure S3 of Supporting Information. HNC cannot be eliminated directly from melamine; one or more hydrogen shifts have to precede this process. Isomer $\mathbf{1 b}$ can decompose to $\mathrm{C}_{2} \mathrm{~N}_{5} \mathrm{H}_{5}$ (a) + HNC via TS19 by the cleavage of two single bonds in the ring, $\mathrm{N}^{1} \mathrm{C}^{2}$ and $\mathrm{C}^{2} \mathrm{~N}^{3}$, and the formation of a new $\mathrm{N}^{1} \mathrm{~N}^{3}$ bond. Transition state TS19 exhibits a highly asynchronous character. From the reactant $\mathbf{1 b}$ to $\mathbf{T S 1 9}$ the $\mathrm{C}^{2} \mathrm{~N}^{3}$ bond is being broken, while the second $\mathrm{N}^{1} \mathrm{C}^{2}$ bond is slightly shortened. The $\mathrm{N}^{1} \mathrm{~N}^{3}$ bond barely starts to form, with the $\mathrm{N}^{1} \mathrm{~N}^{3}$ distance of $2.09 \AA$ in the transition state. After the transition state, $\mathrm{N}^{1} \mathrm{~N}^{3}$ is created and $\mathrm{N}^{1} \mathrm{C}^{2}$ is cleaved giving the $\mathrm{C}_{2} \mathrm{~N}_{5} \mathrm{H}_{5}$ (a) $+\mathrm{HNC}$ products. The barrier at TS19 is calculated to be $134.6 \mathrm{kcal} / \mathrm{mol}$ at the B3LYP/6-31G* level. On the other hand, the reaction heat for 1a $\rightarrow \mathrm{C}_{2} \mathrm{~N}_{5} \mathrm{H}_{5}$ (a) $+\mathrm{HNC}$ is quite low, 76.6 and $72.0 \mathrm{kcal} / \mathrm{mol}$ with the $6-31 \mathrm{G}^{*}$ and cc-pVTZ basis sets, respectively.

Isomer 1c can decompose either to $\mathrm{C}_{2} \mathrm{~N}_{5} \mathrm{H}_{5}$ (c) + HNC through TS20 or to $\mathrm{C}_{2} \mathrm{~N}_{5} \mathrm{H}_{5}$ (b) $+\mathrm{HNC}$ through TS21. The activation energies then increase to 138.8 and $144.6 \mathrm{kcal} / \mathrm{mol}$, respectively, which is parallel to the increase of the reaction endothermicities to 89.4 and $98.3 \mathrm{kcal} / \mathrm{mol}$. If three hydrogen shifts occur prior the decomposition, structure 1d dissociates 
(a)
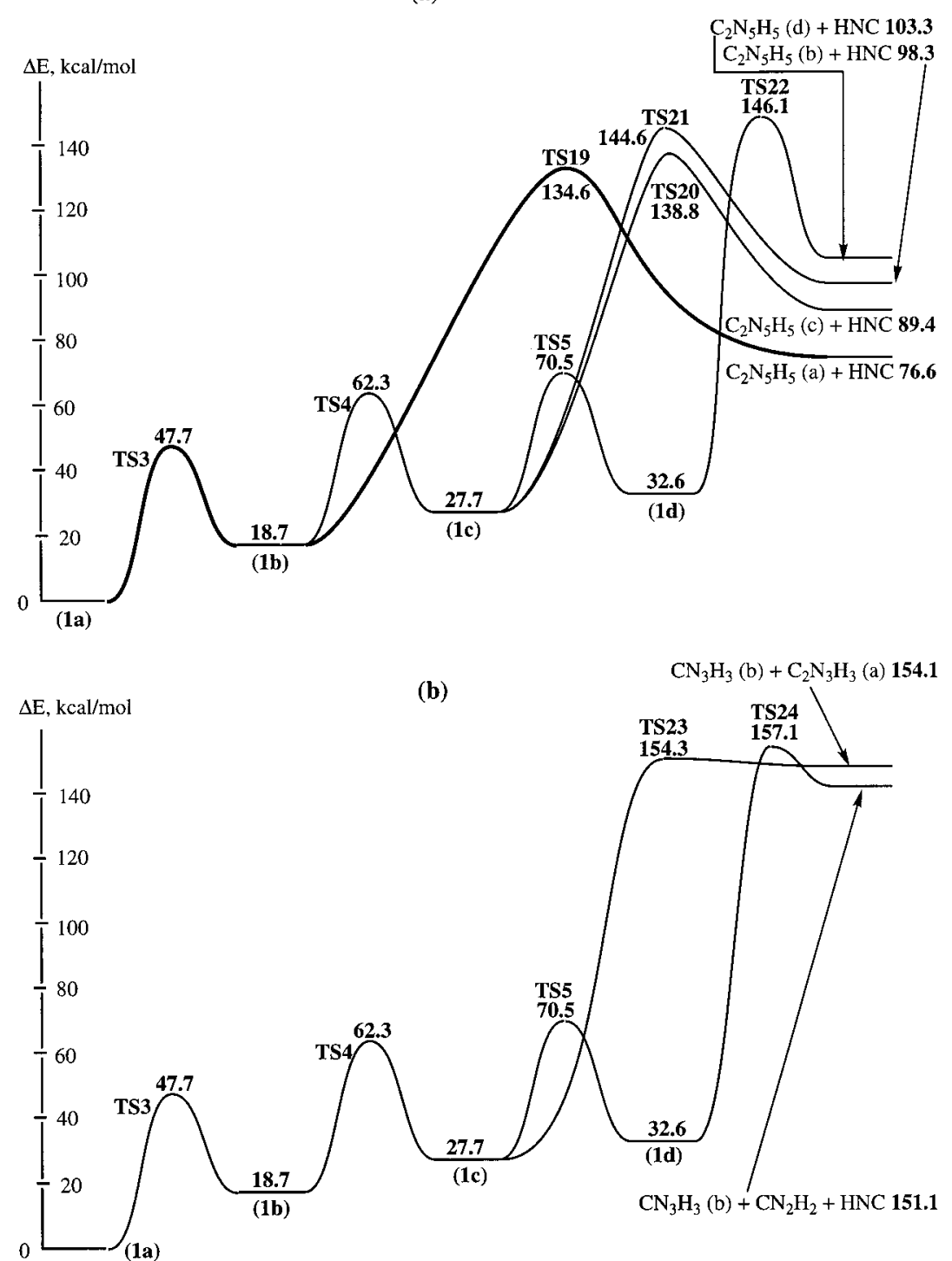

Figure 11. Potential energy surfaces of the $\mathrm{C}_{3} \mathrm{~N}_{6} \mathrm{H}_{6} \rightarrow \mathrm{C}_{2} \mathrm{~N}_{5} \mathrm{H}_{5}+\mathrm{HNC}$ (a) and $\mathrm{C}_{3} \mathrm{~N}_{6} \mathrm{H}_{6} \rightarrow \mathrm{CN}_{3} \mathrm{H}_{3}+$ other products (b) dissociation channels, calculated at the B3LYP/6-31G* level.

to $\mathrm{C}_{2} \mathrm{~N}_{5} \mathrm{H}_{5}$ (d) $+\mathrm{HNC}$ via TS22 with the barrier and endothermicity of 146.1 and $103.3 \mathrm{kcal} / \mathrm{mol}$. All four transition states for the $\mathrm{HNC}$ elimination from $\mathrm{C}_{3} \mathrm{~N}_{6} \mathrm{H}_{6}$ have similar geometries and related to each other by hydrogen shifts. The relative stabilities of the $\mathrm{C}_{2} \mathrm{~N}_{5} \mathrm{H}_{5}$ isomers can change at higher levels of theory. However, we do not expect a change in their order on the energetic scale since the energy differences between them are quite pronounced.

Another minor EI product is $\mathrm{CN}_{3} \mathrm{H}_{2}{ }^{+}(\mathrm{m} / \mathrm{z}=56)$ which can be due to dehydrogenated $\mathrm{CN}_{3} \mathrm{H}_{3}$. In Figure $11 \mathrm{~b}$ we present PES leading from melamine to the $\mathrm{CN}_{3} \mathrm{H}_{3}$ dissociation fragment and the corresponding transition states are shown in Figure S4 of Supporting Information. One pathway involves two sequential hydrogen shifts, 1a $\rightarrow$ TS3 $\rightarrow$ 1b $\rightarrow$ TS4 $\rightarrow$ 1c, followed by the cleavage of the $\mathrm{N}^{1} \mathrm{C}^{2}$ and $\mathrm{C}^{4} \mathrm{~N}^{5}$ single bonds via TS23. In the product, $\mathrm{CN}_{3} \mathrm{H}_{3}(\mathbf{b})$, a new $\mathrm{N}^{3} \mathrm{~N}^{9}$ bond is formed closing a $\mathrm{CN}_{2}$ ring. The reaction is highly endothermic, $154.1 \mathrm{kcal} / \mathrm{mol}$ at $\mathrm{B} 3 \mathrm{LYP} / 6-31 \mathrm{G}^{*}$, and the transition state has a very late character. Accordingly, the reverse barrier is as low as $0.2 \mathrm{kcal} /$ mol. The second product, $\mathrm{C}_{2} \mathrm{~N}_{3} \mathrm{H}_{3}(\mathbf{a})$, is characterized by the $\mathrm{HN}=\mathrm{C}=\mathrm{N}-\mathrm{C}-\mathrm{NH}_{2}$ electronic structure with one carbene-like $\mathrm{C}$ atom. Dehydrogenation of $\mathrm{C}_{2} \mathrm{~N}_{3} \mathrm{H}_{3}$ may give rise to $\mathrm{C}_{2} \mathrm{~N}_{3} \mathrm{H}_{2}{ }^{+}$ $(m / z=68)$ but the major source of the latter should be protonation of $\mathrm{C}_{2} \mathrm{~N}_{3} \mathrm{H}$ produced together with $\mathrm{CN}_{3} \mathrm{H}_{5}$ in one of the major channels. Also, $\mathrm{C}_{2} \mathrm{~N}_{3} \mathrm{H}_{3}$ looks as a natural source of the $\mathrm{C}_{2} \mathrm{~N}_{2} \mathrm{H}^{+}(\mathrm{m} / \mathrm{z}=53)$ ions observed in the $70 \mathrm{eV}$ EI experiments which can be produced by splitting $\mathrm{NH}_{2}$ along the single $\mathrm{C}^{4} \mathrm{~N}^{8}$ bond followed by ionization. However, some other secondary pathways giving $\mathrm{C}_{2} \mathrm{~N}_{2} \mathrm{H}^{+}$also cannot be excluded.

We considered several isomers of $\mathrm{CN}_{3} \mathrm{H}_{3}$ and $\mathrm{C}_{2} \mathrm{~N}_{3} \mathrm{H}_{3}$ which might be formed by the decomposition of $\mathrm{C}_{3} \mathrm{~N}_{6} \mathrm{H}_{6} \mathbf{1 a}-\mathbf{1 d}$. All three structures of $\mathrm{CN}_{3} \mathrm{H}_{3}$ have a $\mathrm{CN}_{2}$ ring and an out-of-ring $\mathrm{CN}$ bond and differ by positions of three hydrogens. Isomer $\mathrm{CN}_{3} \mathrm{H}_{3}$ (b) is the most stable of the three, with a and c, respectively, lying 1.8 and $5.8 \mathrm{kcal} / \mathrm{mol}$ higher at the $\mathrm{B} 3 \mathrm{LYP} /$ 6-31G* level. For $\mathrm{C}_{2} \mathrm{~N}_{3} \mathrm{H}_{3}$, isomer (a) has a linear structure and b includes a $\mathrm{CN}_{2}$ ring. In our calculations, $\mathrm{C}_{2} \mathrm{~N}_{3} \mathrm{H}_{3}$ (a) is 7.1 $\mathrm{kcal} / \mathrm{mol}$ more stable than $\mathbf{b}$. It should be noted that in the present study we have neither exhausted all possibilities for different isomers with the $\mathrm{CN}_{3} \mathrm{H}_{3}$ and $\mathrm{C}_{2} \mathrm{~N}_{3} \mathrm{H}_{3}$ stoichiometry nor reached the highest level of accuracy in the prediction of their relative energies. Both these subjects are beyond our goals.

Despite a careful search, we could not find any other pathways leading from melamine to $\mathrm{CN}_{3} \mathrm{H}_{3}+\mathrm{C}_{2} \mathrm{~N}_{3} \mathrm{H}_{3}$. Instead, 
we located a transition state TS24 (Figure S4 in Supporting Information) connecting $\mathrm{C}_{3} \mathrm{~N}_{6} \mathrm{H}_{6}$ with the triple $\mathrm{CN}_{3} \mathrm{H}_{3}$ (b) + $\mathrm{HNC}+\mathrm{HNCNH}$ products. The overall endothermicity of this channel is $151.1 \mathrm{kcal} / \mathrm{mol}$ at B3LYP/6-31G* and the barrier at TS24 is $157.1 \mathrm{kcal} / \mathrm{mol}$. TS24 has a peculiar ten-member ring structure and is a late transition state. IRC calculations show that TS24 connects the products with the $1 \mathbf{d}$ isomer of $\mathrm{C}_{3} \mathrm{~N}_{6} \mathrm{H}_{6}$. The decomposition occurs by the cleavage of $\mathrm{N}^{1} \mathrm{C}^{2}, \mathrm{C}^{2} \mathrm{~N}^{3}$, and $\mathrm{N}^{5} \mathrm{C}^{6}$ bonds with the formation of $\mathrm{N}^{3} \mathrm{~N} .{ }^{8}$

The $\mathrm{C}_{3} \mathrm{~N}_{5} \mathrm{H}_{4}{ }^{+}$ions $(\mathrm{m} / \mathrm{z}=110)$ which were observed in EI and LDI experiments (in deuterated form for the latter) can be produced by dehydrogenation of $\mathrm{C}_{3} \mathrm{~N}_{5} \mathrm{H}_{5}$. The neutral $\mathrm{C}_{3} \mathrm{~N}_{5} \mathrm{H}_{5}$ fragment, in turn, can be formed from the $\mathbf{1 b}, \mathbf{1 c}$, or $\mathbf{1 d}$ isomers of $\mathrm{C}_{3} \mathrm{~N}_{6} \mathrm{H}_{6}$ by $\mathrm{NH}$ elimination. For example, we consider the elimination of $\mathrm{NH}$ from $\mathbf{1 b}$. The reaction can proceed by simple splitting of the double $\mathrm{C}^{2} \mathrm{~N}^{7}$ bond to form a six-member ring $\mathrm{C}_{3} \mathrm{~N}_{5} \mathrm{H}_{5}$ (a). In this structure, $\mathrm{C}^{2}$ is a carbene-like carbon. The other, more complicated mechanism involves the cleavage of the $\mathrm{N}^{1} \mathrm{C}^{2}$ and $\mathrm{N}^{1} \mathrm{C}^{6}$ single bonds accompanied by the formation the $\mathrm{C}^{2} \mathrm{C}^{6}$ bond. In this case, a five-member ring $\mathrm{C}_{3} \mathrm{~N}_{5} \mathrm{H}_{5}$ (b) isomer is produced. $\mathrm{C}_{3} \mathrm{~N}_{5} \mathrm{H}_{5}(\mathbf{b})$ is significantly more stable than $\mathrm{C}_{3} \mathrm{~N}_{5} \mathrm{H}_{5}$ (a). The reaction endothermicity for $\mathrm{C}_{3} \mathrm{~N}_{6} \mathrm{H}_{6} \mathbf{1 a} \rightarrow$ $\mathrm{C}_{3} \mathrm{~N}_{5} \mathrm{H}_{5}+$ triplet $\mathrm{NH}$ is 142.9 and $110.6 \mathrm{kcal} / \mathrm{mol}$ for the $\mathbf{a}$ and b structures of $\mathrm{C}_{3} \mathrm{~N}_{5} \mathrm{H}_{5}$, respectively, at the B3LYP/6-31G* level. Since the ground-state product is triplet $\mathrm{NH}$, the reaction has to involve a crossing between the singlet and triplet PES. Otherwise the excited singlet $\mathrm{NH}$ would be formed and the heat of the reaction would be $53.5 \mathrm{kcal} / \mathrm{mol}$ higher (at B3LYP/6$31 \mathrm{G}^{*}$ ). If the $\mathrm{NH}$ elimination occurs from $\mathbf{1 c}$ or $\mathbf{1 d}$, other $\mathrm{C}_{3} \mathrm{~N}_{5} \mathrm{H}_{5}$ isomers of the $\mathbf{a}$ - or $\mathbf{b}$-type can be produced, related to the $\mathbf{a}$ and $\mathbf{b}$ structures by hydrogen shifts.

The $\mathrm{CN}_{2} \mathrm{H}_{4}+\mathrm{C}_{2} \mathrm{~N}_{4} \mathrm{H}_{2}$ neutral products can give rise to such ions as $\mathrm{CN}_{2} \mathrm{H}_{3}{ }^{+}(\mathrm{m} / \mathrm{z}=45), \mathrm{CN}_{2} \mathrm{H}_{5}{ }^{+}(\mathrm{m} / \mathrm{z}=47)$, and $\mathrm{C}_{2} \mathrm{~N}_{4} \mathrm{H}_{3}{ }^{+}$ $(\mathrm{m} / \mathrm{z}=83)$, also observed in the EI and LDI experiments. The reaction mechanism leading from melamine to $\mathrm{CN}_{2} \mathrm{H}_{4}+$ $\mathrm{C}_{2} \mathrm{~N}_{4} \mathrm{H}_{2}$ is quite complicated. We expected that these products can be formed directly from structure 1e by the 1,2-hydrogen shift from $\mathrm{N}^{5}$ to $\mathrm{C}^{4}$ with the cleavage of the $\mathrm{C}^{4} \mathrm{~N}^{5}$ bond and the formation of the $\mathrm{N}^{5} \mathrm{~N}^{9}$ bond in $\mathrm{C}_{2} \mathrm{~N}_{4} \mathrm{H}_{2}$. However, the saddle point search in this area of PES gives TS25 which does not involve the hydrogen shift. IRC calculations show that TS25 connects an isomer obtained from 1e by rotation around the $\mathrm{N}^{5} \mathrm{C}^{6}$ bond with structure 11. During the reaction, the $\mathrm{C}^{4} \mathrm{~N}^{5}$ bond is broken and a $\mathrm{N}^{3} \mathrm{~N}^{9}$ single bond is formed. The barrier at TS25 is high, $133.0 \mathrm{kcal} / \mathrm{mol}$ relative to melamine at the B3LYP/6$31 \mathrm{G}^{*}$ level. Structure $1 \mathrm{l}$ lies as high as $106.8 \mathrm{kcal} / \mathrm{mol}$ above 1a. From 11 the reaction can proceed either by the $1,5-\mathrm{H}$ shift from $\mathrm{N}^{5}$ to $\mathrm{C}^{4}$ leading to $\mathrm{CN}_{2} \mathrm{H}_{4}$ (a) $+\mathrm{C}_{2} \mathrm{~N}_{4} \mathrm{H}_{2}$ or by the 1,2 hydrogen shift from $\mathrm{N}^{9}$ to $\mathrm{N}^{3}$ giving the $\mathrm{CN}_{2} \mathrm{H}_{4}$ (b) $+\mathrm{C}_{2} \mathrm{~N}_{4} \mathrm{H}_{2}$ products. $\mathrm{CN}_{2} \mathrm{H}_{4}$ (b) is a carbene structure and is less stable than $\mathrm{CN}_{2} \mathrm{H}_{4}$ (a) by $24.4 \mathrm{kcal} / \mathrm{mol}$. The calculated endothermicity is high as compared to most of the other product channels even for $1 \mathrm{a} \rightarrow \mathrm{CN}_{2} \mathrm{H}_{4}(\mathbf{a})+\mathrm{C}_{2} \mathrm{~N}_{4} \mathrm{H}_{2}, 134.1 \mathrm{kcal} / \mathrm{mol}$ at B3LYP/6$31 \mathrm{G}^{*}$. As a result, this channel is minor in melamine decomposition and we have not studied the last stages following the formation of $\mathbf{1 1 .}$

\section{Conclusions}

We have studied the fragmentation of the melamine molecule via EI, LDI, and CID. In the EI experiments, the melamine molecular ion $\left(\mathrm{C}_{3} \mathrm{~N}_{6} \mathrm{H}_{6}{ }^{+}\right)$is directly formed with 20 and $70 \mathrm{eV}$ energetic electron bombardment. Other fragment ions, such as $m / z=43\left(\mathrm{CN}_{2} \mathrm{H}_{3}{ }^{+}\right), 53\left(\mathrm{C}_{2} \mathrm{~N}_{2} \mathrm{H}^{+}\right), 56\left(\mathrm{CN}_{3} \mathrm{H}_{2}{ }^{+}\right), 68\left(\mathrm{C}_{2} \mathrm{~N}_{3} \mathrm{H}_{2}{ }^{+}\right)$, $83\left(\mathrm{C}_{2} \mathrm{~N}_{4} \mathrm{H}_{3}^{+}\right), 85\left(\mathrm{C}_{2} \mathrm{~N}_{4} \mathrm{H}_{5}^{+}\right), 99\left(\mathrm{C}_{2} \mathrm{~N}_{5} \mathrm{H}_{5}^{+}\right), 110\left(\mathrm{C}_{3} \mathrm{~N}_{5} \mathrm{H}_{4}^{+}\right)$, etc., are subsequently generated from the metastable parent molecular ion. This speculation was supported by our CID measurements.

In the LDI experiments, the melamine molecule is pumped to the $1^{1} \mathrm{~A}^{\prime \prime}$ and $2^{1} \mathrm{~A}^{\prime}$ excited electronic states with 266 and 193 $\mathrm{nm}$ lasers, respectively. In view of the same fragment ions $(\mathrm{m} / \mathrm{z}$ $=43,45\left(\mathrm{CN}_{2} \mathrm{H}_{5}{ }^{+}\right), 60\left(\mathrm{CN}_{3} \mathrm{H}_{6}{ }^{+}\right), 85$, and $\left.127\left(\mathrm{C}_{3} \mathrm{~N}_{6} \mathrm{H}_{7}{ }^{+}\right)\right)$ resulting from different excited electronic states, the fragmentation of melamine is concluded to be preceded by an internal conversion to its ground PES. Theoretical calculations of the low-lying electronic states of melamine are consistent with the absorption spectra. The theoretical excitation energies of electronic states of melamine and the spectroscopic identification have assisted the interpretation of the LDI experimental data. It should be noted that only a fraction of the products in LDI are ions which can be detected in the mass spectra. Some fragments could be neutral and are not seen using the technique.

To account for the dissociation mechanism of melamine, an amino hydrogen shift to the triazine ring to destroy the aromaticity of melamine is proposed. The most energetically favorable dissociation mechanism involves a series of hydrogen shifts from the out-of-ring nitrogens to the $\mathrm{N}$ atoms of the ring leading first to the ring opening and eventually to the fragmentation of the molecule: $1 \mathrm{a} \rightarrow$ TS3 $\rightarrow \mathbf{1 b} \rightarrow$ TS4 $\rightarrow 1 \mathrm{c} \rightarrow$ TS6 $\rightarrow \mathbf{1 e} \rightarrow \mathbf{1 f} \rightarrow$ TS7 $\rightarrow 1 \mathrm{~g} \rightarrow \mathrm{TS} 10 \rightarrow \mathbf{1 k} \rightarrow \mathrm{CN}_{3} \mathrm{H}_{5}+\mathrm{C}_{2} \mathrm{~N}_{3} \mathrm{H}$. The rate-determining step for this mechanism is the third hydrogen shift accompanied with the ring opening at TS6 and the corresponding barrier is $93.6 \mathrm{kcal} / \mathrm{mol}$ at our best B3LYP/ cc-pVTZ level. The $\mathrm{CN}_{3} \mathrm{H}_{5}+\mathrm{C}_{2} \mathrm{~N}_{3} \mathrm{H}$ product channel is found to be $64.7 \mathrm{kcal} / \mathrm{mol}$ endothermic. The other two mechanisms, $1 \mathrm{a} \rightarrow \mathrm{TS1} \rightarrow 3 \mathrm{NCNH}_{2}$, the concerted triple dissociation, and $\mathbf{1 a} \rightarrow \mathrm{TS3} \rightarrow \mathbf{1 b} \rightarrow$ TS15 $\rightarrow \mathrm{C}_{2} \mathrm{~N}_{4} \mathrm{H}_{4}(\mathbf{a})+\mathrm{HNCNH}$, have higher barriers, $104.8 \mathrm{kcal} / \mathrm{mol}$ (at TS1) and $105.6 \mathrm{kcal} / \mathrm{mol}$ (at TS15) and are endothermic by 75.7 and $85.1 \mathrm{kcal} / \mathrm{mol}$, respectively. All other product channels have significantly higher activation energies. Therefore, the neutral melamine molecules in the ground electronic state should give $\mathrm{CN}_{3} \mathrm{H}_{5}+\mathrm{C}_{2} \mathrm{~N}_{3} \mathrm{H}$ as the major dissociation products. After protonation, $\mathrm{CN}_{3} \mathrm{H}_{5}$ gives rise to the $\mathrm{CN}_{3} \mathrm{H}_{6}{ }^{+}$molecular ions $(\mathrm{m} / \mathrm{z}=60)$ which is the most intense peak in the LDI mass spectra. On the other hand, no or weak $m / z=68\left(\mathrm{C}_{2} \mathrm{~N}_{3} \mathrm{H}_{2}{ }^{+}\right)$peaks were observed in the spectra and this fact requires further investigation. The $\mathrm{C}_{2} \mathrm{~N}_{3} \mathrm{H}_{2}{ }^{+}$peaks were seen in the EI mass spectra. The other signals in the LDI spectra are due to $\mathrm{CN}_{2} \mathrm{H}_{3}{ }^{+}(\mathrm{m} / \mathrm{z}=43), \mathrm{C}_{2} \mathrm{~N}_{4} \mathrm{H}_{5}{ }^{+}(\mathrm{m} / \mathrm{z}=85)$, and $\mathrm{CN}_{2} \mathrm{H}_{5}{ }^{+}(\mathrm{m} / \mathrm{z}=45)$ which can be obtained by protonation of the neutral $\mathrm{CN}_{2} \mathrm{H}_{2}, \mathrm{C}_{2} \mathrm{~N}_{4} \mathrm{H}_{4}$, and $\mathrm{CN}_{2} \mathrm{H}_{4}$ fragments, respectively.

All the molecular ions observed in EI can be produced from major and minor neutral fragments of melamine dissociation. Our calculations demonstrate the reaction pathways leading to these fragments and predict the corresponding activation energies. In the EI experiments, $\mathrm{CN}_{2} \mathrm{H}_{3}{ }^{+}$and $\mathrm{C}_{2} \mathrm{~N}_{4} \mathrm{H}_{5}{ }^{+}$are the major products. This result implies that the dissociation mechanism could be different from the dissociation on neutral PES and the reaction is likely to occur on the ionic PES, after the $\mathrm{C}_{3} \mathrm{~N}_{6} \mathrm{H}_{6}{ }^{+}$ molecular ion is formed by ionization of melamine with energetic electrons. To verify this hypothesis, a similar study of the $\mathrm{C}_{3} \mathrm{~N}_{6} \mathrm{H}_{6}{ }^{+}$PES would be needed. We expect this surface to be qualitatively similar but the relative barrier heights for the critical transition states can change.

The dissociation mechanism of melamine is demonstrated to be distinct from that of s-triazine. This owes to the presence of mobile hydrogen atoms of the amino groups which can be shifted to the $\mathrm{N}$ atoms of the aromatic ring. The sequential 
hydrogen shifts break the aromaticity of the melamine molecule and enhance the decomposition process.

Acknowledgment. A.M.M. is grateful to Academia Sinica for his fellowship at IAMS. This work is supported, in part, by the National Science Council of ROC under Grants NSC-872113-M-001-032 and NSC-87-2113-M-001-028-CT. We also gratefully acknowledge the support from the research fund of the China Petroleum Corporation, ROC.

Supporting Information Available: Figures showing optimized geometries (bond lengths in angstroms) for various isomers of $\mathrm{C}_{3} \mathrm{~N}_{6} \mathrm{H}_{6}$, various products of melamine dissociation, transition states for the $\mathrm{C}_{3} \mathrm{~N}_{6} \mathrm{H}_{6} \rightarrow \mathrm{C}_{2} \mathrm{~N}_{5} \mathrm{H}_{5}+\mathrm{HNC}$ dissociation channel, and transition states for the dissociation channels leading to $\mathrm{CN}_{3} \mathrm{H}_{3}$ and $\mathrm{CN}_{2} \mathrm{H}_{4}+\mathrm{C}_{2} \mathrm{~N}_{4} \mathrm{H}_{2}$. This information is available free of charge via the Internet at http://pubs.acs.org.

\section{References and Notes}

(1) Wang, Y.-L.; Mebel, A. M.; Wu, C.-J.; Chen, Y.-T.; Lin, C.-E.; Jiang, J.-C. J. Chem. Soc., Faraday Trans. 1997, 93, 3445.

(2) (a) Verite, P.; Andre, D.; Menager, S.; Lafont, O. J. Chromatogr. 1992, 578, 134. (b) Heil, G.; Krauter, J.; Hartll, M.; Beyerjohannoboke, E.; Gunsilius, E.; Ganser, A.; Kurrel, E.; Westphalfrosch, C. Leukemia 1993, 7, 1466.

(3) (a) Plimmer, J. R.; Kearney, P. C.; Klingebiel, U. I. J. Agric. Food. Chem. 1971, 19, 572. (b) Wehner, D. J.; Martin, D. L. Commun. Soil Sci. Plant Anal. 1989, 20, 1659.

(4) Pelizzetti, E.; Maurino, V.; Minero, C.; Carlin, V.; Pramauro, E.; Zerbinati, O.; Tosato, M. L. Environ. Sci. Technol. 1990, 24, 1559.

(5) Stoner, C. E.; Brill, T. B. Combust. Flame 1991, 83, 302.

(6) Kuryla, W. C.; Papa, A. J. Flame Retardancy of Polymeric Materials; Dekker: New York, 1973-1979; Vol. 1-5.

(7) Cullis, C. F.; Hirschler, M. M. The Combustion of Organic Polymers; Clarendon Press: Oxford, 1981.

(8) Ondrey, G. S.; Bersohn, R. J. Chem. Phys. 1984, 81, 4517. 4521 .

(9) Goares, S. R.; Chu, J. O.; Flynn, G. W. J. Chem. Phys. 1984, 81,

(10) Osamura, Y.; Unno, M.; Hashimoto, K. J. Am. Chem. Soc. 1987, 109,1370 13941

(11) Geto, T.; Harrison, J. A.; Huber, J. R. J. Phys. Chem. 1996, 100,

(12) Deng, J. P.; Ju, D. D.; Her, G. R.; Mou, C. Y.; Chen, C. J.; Lin, Y. Y.; Han, C. C. J. Phys. Chem. 1993, 97, 11575.

(13) H.-M. Hung, C.-C. Han and S. H. Lin, J. Cluster Science 1995, 6, 533.

(14) Foresman, J. B.; Head-Gordon, M.; Pople, J. A.; Frisch, M. J. J. Phys. Chem. 1992, 96, 135.

(15) Hehre, W. J.; Ditchfield, R.; Pople, J. A. J. Chem. Phys. 1992, 56 , 2257.

(16) Krishnan, R.; Frisch, M.; Pople, J. A. J. Chem. Phys. 1980, 72, 4244.

(17) (a) Andersson, K.; Malmqvist, P.-Å.; Roos, B. O.; Sadlej, A. J.; Wolinski, K. J. Phys. Chem. 1990, 94, 5483. (b) Andersson, K.; Malmqvist, P.-Å.; Roos, B. O. J. Chem. Phys. 1992, 96, 1218.

(18) Pierloot, K.; Dumez, B.; Widmark, P.-O.; Roos, B. O. Theor. Chim. Acta, 1995, 90, 87.

(19) (a) Becke, A. D. J. Chem. Phys. 1993, 98, 5648. (b) Lee, C.; Yang, W.; Parr, R. G. Phys. Rev. 1988, B37, 785.

(20) Gonzalez, C.; Schlegel, H. B. J. Phys. Chem. 1989, 90, 2154.

(21) Dunning, T. H. J. Chem. Phys. 1989, 90, 1007.

(22) Frisch, M. J.; Trucks, G. W.; Schlegel, H. B.; Gill, P. M. W. Johnson, B. G.; Robb, M. A.; Cheeseman, J. R.; Keith, T.; Petersson, G. A.; Montgomery, J. A.; Raghavachari, K.; Al-Laham, M. A.; Zakrzewski, V. G.; Ortiz, J. V.; Foresman, J. B.; Cioslowski, J.; Stefanov, B. B.; Nanayakkara, A.; Challacombe, M.; Peng, C. Y.; Ayala, P. Y.; Chen, W.; Wong, M. W.; Andres, J. L.; Replogle, E. S.; Gomperts, R.; Martin, R. L.; Fox, D. J.; Binkley, J. S.; Defrees, D. J.; Baker, J.; Stewart, J. P.; HeadGordon, M.; Gonzalez, C.; Pople, J. A. GAUSSIAN 94, Revision D.4; Gaussian, Inc.; Pittsburgh: PA, 1995.

(23) Andersson, K.; Blomberg, M. R. A.; Fulscher, M. P.; Karlstrom, G.; Kello, V.; Lindh, R.; Malmqvist, P.-Å.; Noga, J.; Olsen, J.; Roos, B. O.; Sadlej, A. J.; Siegbahn, P. E. M.; Urban, M.; Widmark, P.-O., MOLCAS3; University of Lund: Sweden, 1995.

(24) Pai, S. V.; Chabalowski, C. F.; Rice, B. M. J. Phys. Chem. 1996, 101, 15368 .

(25) Serrano-Andres, L.; Merchan, M.; Nebot-Gil, I.; Lindh, R.; Roos, B. O. J. Chem. Phys. 1993, 98, 3151.

(26) Han, C.-C., Wang, R.-W., and Lee, T.-S. J. Chin. Chem. Soc. 1998, $45,229$.

(27) Wang, Y.; Pittman, C. U.; Saebo, S. J. Org. Chem. 1993, 58, 3085. (28) Meier, R.; Coussens, B. J. Mol. Struct. (THEOCHEM) 1990, 68 303.

(29) Palmer, M. H.; Blair-Fish, J. A. Z. Naturforsch. A 1994, 49, 146. 